\title{
Numerical Simulation on Double-nozzle Spray Evaporation of Desulfurization Wastewater
}

\author{
Hong Xu ${ }^{1}$, Shuqin Feng ${ }^{2 *}$, Liehui Xiao ${ }^{3}$, Yazhen Hao ${ }^{4}$, Xiaoze Du ${ }^{2^{*}}$ \\ 1 CHN Energy Jilin Jiangnan Thermal Power Co., Ltd, Jilin 132011, China; Email: xuhong_chn@163.com (H. \\ G.) \\ 2 Key Laboratory of Condition Monitoring and Control for Power Plant Equipment (North China Electric \\ Power University), Ministry of Education, Beijing 102206; China \\ 3 Guangdong Provincial Key Laboratory of Distributed Energy Systems, Dongguan University of \\ Technology, Dongguan 523808, China \\ 4 CHN Energy Longyuan Blue Sky Energy Conversation Technology Co., Ltd., Beijing 102206, China

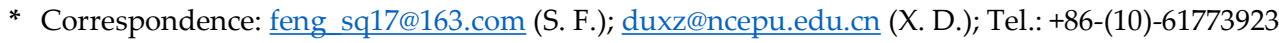

\begin{abstract}
To achieve the near zero emission of wastewater in the flue gas desulfurization (FGD) system in coal-fired power plant and better utilize the exhaust heat from flue gas, a feasible technology of spraying FGD wastewater in the flue duct for evaporation is discussed in the present study. A full-scale influencing factor investigation on the wastewater droplet evaporation performance is established under the Eulerian-Lagrangian model numerically. The dominant factors, including the characters of wastewater droplets, flue gas and the spray nozzles were analyzed under different conditions, respectively. Considering the multiple factors and conditions in the process, a Least-Square support vector machine (LSSVM) model is introduced to predict the evaporation rate based on the numerical results. Conclusions are made that the flue gas temperature and droplet diameter are of great importance in the evaporation process. The spray direction of droplet parallel with the flue gas flow direction is profitable for the dispersion of droplet, resulting the maximal evaporation rate. A double-nozzle arrangement optimized with relatively small flow rate is recommended. The LSSVM model can accurately predict the evaporation rate using the numerical results with different conditions.
\end{abstract}

Keywords: FGD wastewater spay evaporation; atomized droplet characteristics; Least-Square support vector machine prediction model

\section{Introduction}

Wet limestone flue gas desulfurization technology is most widely used in flue gas desulfurization (FGD) systems for coal-fired power plant to meet the increasingly restrict environmental policy [1]. During the desulfurization, a great amount of wastewater are produced due to the gypsum dehydration and the scrubbing of the absorption tower [2]. The FGD wastewater is acidic and contains massive chlorine ions, fluoride ions and heavy metals, etc. Therefore, the pretreated of FGD wastewater is essential before discharge. [3-5]. The traditional and widely used method for FGD wastewater treatment is chemical sedimentation [2,6]. However, this method is difficult to completely remove the chlorine ions which could corrode the desulfurization system [2,7]. Moreover, the trace element such as selenium is also hardly removed [8]. In addition, the investment of equipment and the maintenance cost is very expensive [9].

Nowadays, a low-cost and high-efficient technology that utilizes the flue gas to evaporate FGD wastewater has drawn attentions from worldwide [2,3,9]. The FGD wastewater mixes with the compressed air firstly, and then sprays into the flue duct. The atomized droplets are quickly evaporated by the high-temperature flue gas to achieve a near zero emission. As shown in Figure 1, the FGD wastewater is atomized into droplets with the help of compressed air through the nozzle and injected into the flue duct tail of the boiler [10]. Then the wastewater is evaporated instantaneously due to absorbing the exhaust heat from flue gas. Finally, dry matters in wastewater are separated and collected in the electrostatic precipitator and discharged with fly ash [11]. 


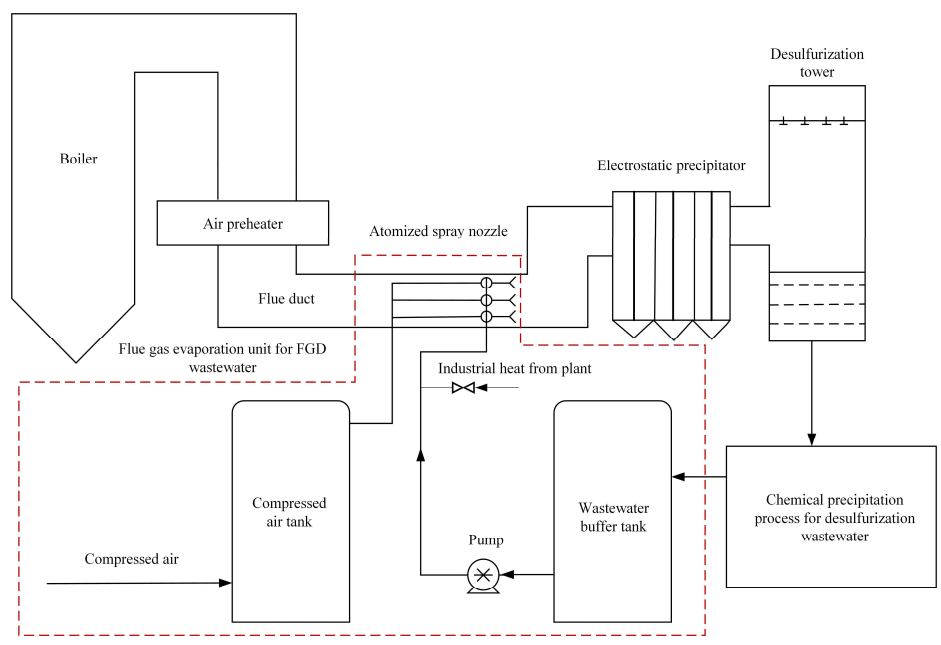

Figure 1. Typical treatment process of spraying FGD wastewater in flue duct for evaporation

The advantages of the FGD wastewater spray evaporation process include the efficient use of the exhaust flue gas heat and no extra equipment setup in the desulfurization system. Moreover, the heavy metal and chloride ions are sedimented and crystalized into dry matters without polluting the environment. The key point to the feasibility of this method is that the atomized wastewater droplets could be totally evaporated before reaching the flue duct wall and downstream devices. If not, the wall or the devices would be destroyed due to the high corrosion of the wastewater. Thus, the spray evaporation performance is critical to this technology. However, the droplets evaporation is a nonlinear, multi-factor effected and complex process. Therefore, the researchers studied the spray evaporation from different perspectives by both experiment $[10,12-14]$ and numerical simulation [1520]. Deng et al. [15] investigated how the nozzle position arrangement and the flue gas temperature effected the evaporation through the computational fluid dynamic simulation methods. Results showed that with a longer flue duct distance and a higher flue gas temperature the droplets evaporation rate increases. Tissot et al. [18] found that when the spray direction is opposite to the air flow, the droplets can achieve a better dispersion, which is benefit to droplets evaporation. Kim et al. [21] pointed out that the evaporation performance is enhanced with a higher ambient pressure and the effect is more dominant with a higher ambient temperature. Alkhedhair et al. [22-24] investigated the water spray pre-cooling system numerically and found that the droplet dispersion is important in the evaporation process with low inlet air velocity and small droplet diameter distribution. Zhang et al. [25] conducted a numerical simulation and built a 3D crystallization tower model to investigate the droplet evaporation. Results showed that the initial droplets diameter and the mass flow rate of the flue gas both impact on the evaporation process. Hou et al. [26] studied the characteristic of multi-nozzle spray cooling process using CFD method based on the air flow and the liquid collision dynamics. They found that the nozzle inlet pressure, the nozzle-to-face distance, the mass flow rate and the number of nozzles are the main factors influencing the evaporation performance.

Although some factors were analyzed in each mentioned literature, a comprehensive research contains multi-parameters aiming at improving the spray evaporation performance is hardly found. In the practical situation, the evaporation process of FGD wastewater is a complex gas-liquid flow influenced by several conditions, including the characteristics of flue gas and wastewater droplets, as well as the interaction between each other. Thus, it is hard to take all the impact factors into consideration to optimize the spray evaporation. In order to solve this problem, the Least Squares Support Vector Machine (LSSVM) is a feasible approach. LSSVM is a regression way with the nonlinear and black-box character based on the structural risk minimization principle [27]. The typical Support Vector Machine (SVM) is required to solve quadratic programming problem for optimization while the LSSVM simplifies the process by solving linear sets of equations under multiple constraint conditions and massive sample problem. By using the LSSVM method, the result 
error and computational burden of the optimization process are reduced. The LSSVM method processes great robustness and excellent generalization, which makes it suitable for nonlinear optimization and high-dimension data sequence prediction in many applications [28-30]. According to the reviewed researches, applying the LSSVM method into predicting and optimizing the FGD wastewater spray evaporation treatment is seldomly found.

In this study, a combined Eulerian-Lagrangian mathematical model to evaluate the evaporation behavior of the FGD wastewater in the flue duct is established. A full-scale investigation of the influencing factors such as the full cone angle of the nozzle, the flue gas and atomized wastewater droplets characteristics, the interaction between the gas-liquid flow, will be analyzed. Our previous work [16]conducted single nozzle arrangement performance on parameters effected the evaporation process while in the present study the improves double-nozzle condition will be fully investigated. With the obtained numerical data, a LSSVM model is established to predict the wastewater droplets evaporation performance and optimize the influencing factors. The full-scale investigation and results are helpful for better understanding the FGD wastewater spray evaporation technology and providing a design scheme in the practical application.

\section{Physical model and numerical approach}

As shown in Figure 1, the cuboid shaped flue duct between the air preheater and the electrostatic precipitator is selected as the physical model. In the present study, for the purpose of better selecting and optimizing the spray nozzle arrangement in the practical power plant conditions, a doublenozzle system is chosen to investigate the atomized droplets evaporation character and the interference between nozzles. Figure 2 is the 3D physical model with the channel length of $10 \mathrm{~m}$ and the cross-section area of $3 \times 3 \mathrm{~m}^{2}$. The origin of the coordinate system in this model is placed at the center of the cross-section $0.5 \mathrm{~m}$ away from the inlet along the spray direction. Two solid cone spray nozzles are installed at the origin of the coordinate along with the $z$-axis and atomized droplets spread in three dimensions.

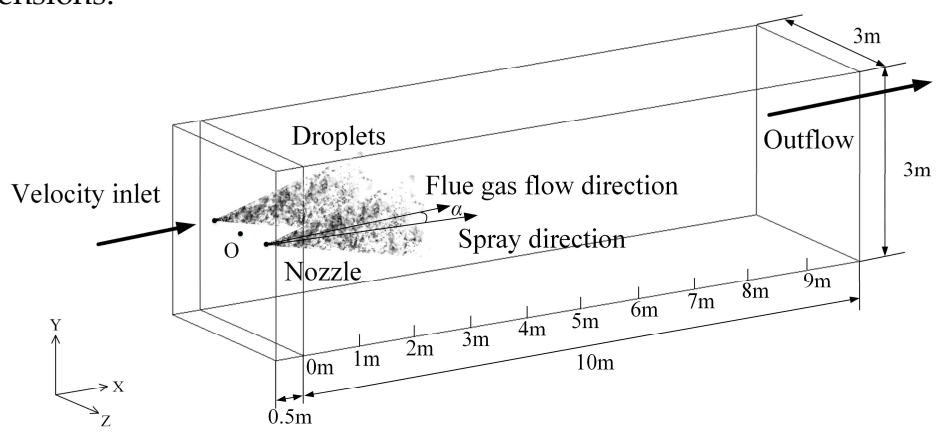

Figure 2. Physical model of the numerical simulation

\subsection{Governing equations for atomized droplets and flow field}

A combined Eulerian-Lagrangian model is selected to simulate the atomized droplets evaporation performance since the process is a gas-liquid two-phase flow. The continuous phase (flue gas) heat and mass transfer character is described in the Eulerian coordinate. The discrete phase (atomized droplets) evaporation behavior is investigated in the Lagrangian coordinate.

\subsubsection{Continuous phase (flue gas)}

During the evaporation process, massive atomized droplets are atomized and injected into flue gas and the effect of droplets evaporation on flue gas is nonnegligible so that the droplet source terms need to be included into the flue gas governing equations. A time-averaged Navier-Stokes conservation equation using standard $k-\varepsilon$ model is present to model the turbulent effect of flue gas $[31,32]$. The governing equations incorporated with droplet source terms are described as followed, 


$$
\begin{gathered}
\frac{\partial}{\partial x_{i}}\left(\rho u_{i}\right)=S_{m} \\
\frac{\partial}{\partial x_{j}}\left(\rho u_{i} u_{j}\right)=\frac{\partial}{\partial x_{j}}\left[\mu_{e f f}\left(\frac{\partial u_{i}}{\partial x_{j}}+\frac{\partial u_{j}}{\partial x_{i}}\right)-\frac{2}{3} \mu_{e f f} \delta_{i j}\left(\frac{\partial u_{k}}{\partial x_{k}}\right)\right]-\frac{\partial P}{\partial x_{i}}+\rho g_{i}+S_{m o} \\
\frac{\partial}{\partial x_{i}}\left(\rho u_{i} E\right)=-P \frac{\partial u_{i}}{\partial x_{i}}+\frac{\partial}{\partial x_{i}}\left(k_{e f f} \frac{\partial T_{f}}{\partial x_{i}}+u_{j}\left(\tau_{i j}\right)_{e f f}\right)+\frac{\partial}{\partial x_{i}}\left(\sum_{j^{\prime}=1}^{n} h_{j^{\prime} J_{j^{\prime}}}\right)+S_{e} \\
\frac{\partial}{\partial x_{i}}\left(\rho u_{i} Y_{j^{\prime}}\right)=-\frac{\partial J_{j^{\prime}, i}}{\partial x_{i}}+S_{m}
\end{gathered}
$$

where $J_{j^{\prime}, i}$ is the diffusion flux of $j^{\prime}, S_{m}$ is the droplet mass source term, $S_{m o}$ is the droplet momentum source term, $S_{e}$ is the droplet energy source term. Since the effect of the droplets on flue gas is nonnegligible, the above-mentioned source terms are firstly calculated under the Lagrangian coordinate by the volume average method and then united into the continuous phase equations under the Eulerian coordinate.

\subsubsection{Discreate phase (atomized droplets)}

The FGD wastewater injected from the nozzle will be atomized into particles in a short time. Temperature difference exists between the droplet and flue gas so that once these two parts contacts with each other the heat and mass transfer will happen. The droplets motion are traced in terms of parcels for the purpose of simplifying the calculation process and reducing the computational burden. It is under the assumption that every parcel contains a serials number of droplet particles possess the same characteristics, therefore the droplets parcel evaporation can be represented by a single droplet. Additionally, the atomized evaporation process is simplified as followed. During the whole evaporation process the atomized droplets remain spherical shape. The droplet latent heat of evaporation, specific heat and surface tension will change along with the droplet temperature. The effect of radiation heat transfer on the evaporation process is ignored. The internal circulation and thermal resistance of the droplet is neglected. Also, it is under the assumption that during the evaporation process the heat and mass transfer mechanism of droplet parcels is consistent with the single droplet evaporation mechanism. Therefore, the heat absorption rate of every droplet in the parcel can be described through the single droplet energy equation,

$$
m_{d} c_{d} \frac{d T_{d}}{d t}=h_{c} A_{d}\left(T_{f}-T_{d}\right)+\frac{d m_{d}}{d t} L_{h}
$$

where $m_{d}, c_{d}, T_{d}, A_{d}$ is the droplet mass, specific heat, temperature and surface area, respectively. $L_{h}$ is the water evaporation latent heat, $T_{f}$ is the flue gas temperature, $h_{c}$ is the convective heat transfer coefficient, which can be obtained by the Ranz-Marshell correlation [33],

$$
N_{u}=d \frac{h_{c} d_{d}}{k_{f}}=\frac{\ln \left(1+B_{T}\right)}{B_{T}}\left(2.0+0.6 \operatorname{Re}_{d}^{\frac{1}{2}} \operatorname{Pr}^{\frac{1}{3}}\right)
$$

where $N_{u}$ is the Nusselt number of the flue gas, $P_{r}$ is the flue gas Prandtl number, $k_{f}$ is the flue gas thermal conductivity, $d_{d}$ is the instantaneous droplet average diameter, $R e_{d}$ is the Reynolds number of the droplet based on the droplet velocity. $B_{T}$ is the thermal Spalding number which under the assumption that is equal to the mass Spalding number $B_{m}$,

$$
B_{T}=B_{m}=\frac{Y_{j^{\prime}, s}-Y_{j^{\prime}, f}}{1-Y_{j^{\prime}, s}}
$$

where $Y_{j^{\prime}, s}$ is the vapor mass fraction of species $j^{\prime}$ on the droplet surface, $Y_{j^{\prime}, f}$ is the vapor mass fraction of species $j^{\prime}$ around the surrounding flue gas, $d m_{d} / d t$ is the mass flow rate that droplet transfer to the flue gas through evaporation, which is used to describe the droplet evaporation rate and expressed as,

$$
\frac{d m_{d}}{d t}=k_{c} A_{d} \rho_{f} \ln \left(1+B_{m}\right)
$$

where $\rho_{f}$ is the flue gas density, $k_{c}$ is the mass transfer coefficient which can be calculated by the Sherwood correlation[34] [35],

$$
S h=\frac{k_{c} d_{d}}{D_{m}}=2.0+0.6 R e_{d}^{\frac{1}{2}} S c^{\frac{1}{3}}
$$


where $S h$ is the Sherwood number, $S c$ is the Schmidt number, $D_{m}$ is the vapor diffusion coefficient.

The Lagrangian method tracks the droplet evaporation by combining the motion equations with the influence of relative forces act on the discrete droplet in flue gas. According to the assumption mentioned earlier that all the atomized droplets have independent characteristic and remain spherical shape during the evaporation process, it is concluded that the changes on the droplet velocity and direction are only caused by drag force and gravity. The motion equation of a single droplet is described as [36,37],

$$
\frac{d \overrightarrow{u_{d}}}{d t}=F_{D}\left(\overrightarrow{u_{f}}-\overrightarrow{u_{d}}\right)+\frac{\overrightarrow{\mathrm{g}}\left(\rho_{d}-\rho_{f}\right)}{\rho_{d}}
$$

where $u_{f}$ is the flue gas velocity, $u_{d}$ is the droplet velocity, $\vec{g}$ is the gravity acceleration, $F_{D}\left(\overrightarrow{u_{f}}-\overrightarrow{u_{d}}\right)$ is the drag force act on droplet, which is described in the form of drag force coefficient [38],

$$
F_{D}=\frac{18 \mu}{\rho_{d} d_{d}^{2}} \frac{C_{D} R e_{d}}{24}
$$

where $C_{D}$ is the drag force coefficient which can be expressed as, with the different range of Reynolds number [39],

the gravity of droplet is described as,

$$
C_{D}= \begin{cases}0.424 & R_{e}>1000 \\ \frac{24}{R_{e}}\left(1+\frac{1}{6} R_{e}^{0.67}\right) & R_{e} \leq 1000\end{cases}
$$

where $V_{d}$ is the volume of droplet.

$$
G=m_{d} \overrightarrow{\mathrm{g}}=\rho_{d} V_{d} \overrightarrow{\mathrm{g}}
$$

The O'Rourke method is used to calculated the droplet collision and coalescence probability, time and results. Based on the collision size conception, the O'Rourke method with second order accuracy assumes that collision only happens between the droplets in the same continuous grid. The droplet collision probability distribution follows a Poisson distribution and described as,

$$
P(n)=e^{-\bar{n}} \frac{\bar{n}^{n}}{n !}
$$

where $n$ is the collisions time of droplets with different diameter.

\subsection{Boundary conditons and grid sensitivity discussion}

\subsubsection{Boundary conditions for both continuous and discrete phase}

In the present study, the impact of solid particles in wastewater droplets on the evaporation process is assumed to be neglected, while the collision and coalescence between droplet particles are taken into consideration.

The flue gas from a 300MW coal-fired power plant with the condition of temperature $T_{f}=403.15$ $\mathrm{K}$ and velocity $u_{f}=9 \mathrm{~m} / \mathrm{s}$ is selected as the calculation setup. The flue gas density, specific heat, thermal conductivity under standard atmospheric pressure are $0.8894 \mathrm{~kg} / \mathrm{m}^{3}, 1.0767 \mathrm{~kJ} /(\mathrm{kg} \cdot \mathrm{K})$, $3.394 \times 10^{-2} \mathrm{~W} /(\mathrm{m} \cdot \mathrm{K})$, respectively. The gravitational acceleration is set as $-9.81 \mathrm{~m} / \mathrm{s}^{2}$ along with the $\mathrm{y}-$ axis positive direction. The inlet boundary condition for flue gas is set as velocity inlet. The outlet boundary condition is set as outflow and the pressure of the exit is described as atmospheric pressure. All the computational domain is set as adiabatic wall with the non-slipping velocity boundary condition.

The FGD wastewater temperature is $323.15 \mathrm{~K}$ and the density is $1074 \mathrm{~kg} \mathrm{~m}^{-3}$. The wastewater

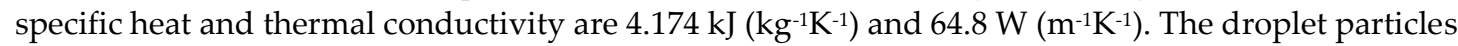
are injected into the flue duct through two solid-cone spray nozzles with the radius of $0.02 \mathrm{~m}$. This type of nozzle can adjust the flow rate, spray angle and spray direction independently to meet the various conditions. The inlet and outlet boundary conditions are set as escape and the flue duct wall boundary condition is set as trap. The trap boundary condition requires that the simulation is stopped and excluded once from the field the droplet particles hit the wall. 


\subsubsection{Grid sensitivity discussion}

GAMBIT is used in gridding the physical model and for the purpose of accurately simulate the mass, heat and momentum transfer between droplets and flue gas, the grid is refined near the nozzle and in the diffusion area. The flow field is symmetrical and regular shaped so that the hexahedral meshes are constructed for computational accuracy and speed.

Under the condition in a double-nozzle system of flue gas temperature $403.15 \mathrm{~K}$, single nozzle flow rate $30 \mathrm{~L} / \mathrm{h}$, simulations of droplet evaporation rate with different grids size are conducted at $x$ $=3 \mathrm{~m}$ cross-section in the flue duct. Grid sensitivity is analyzed with the size of $0.01-0.1 \mathrm{~m}$ and the number of cells about $0.64,1.01,1.26,2.51,3.14,4.18$ and 5.01 million. Figure 3 shows the effect of calculation grid numbers on the droplet evaporation rate and indicates that the evaporation rate at $x$ $=3 \mathrm{~m}$ cross-section rises up with the increment of grid numbers at first and then maintains steady within the grid number range of 1.26-4.18 million. The deviation value of evaporation rate on simulations with grid number of 1.26 million and 3.14 million is less than $1 \%$, which is within the engineering application error range.

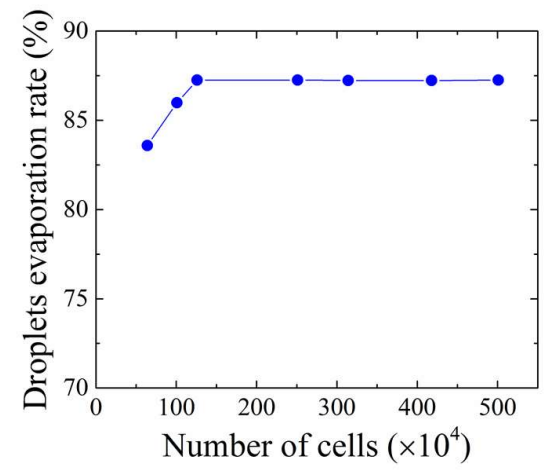

Figure 3. Grid sensitivity test on effect of the evaporation rate

In order to ensure the simulation accuracy while reduce the computational burden, the grid structure is selected with size of $0.1 \mathrm{~m}$ in the inlet area and $0.02 \mathrm{~m}$ in the refined area (near the nozzles and in the flow field along the spray direction), the number of grids is 2.51 million. Figure 4 is the regional grid structure schematic diagram of the double-nozzle model.

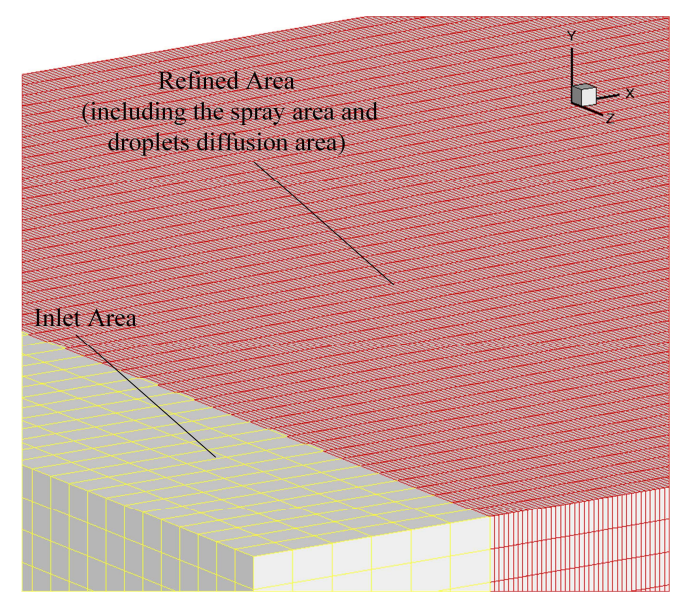

Figure 4. Schematic diagram of regional grid structure on the double-nozzle physical model

\subsection{Numerical approach and experimental validation}

\subsubsection{Numerical approach}


The FGD wastewater evaporation characteristics are simulated under a combined EulerianLagrangian approach. The continuous flue gas is treated as an incompressible turbulent flow and the Reynolds Average Navier-Stokes equation is utilized here to describe the turbulent and heat transfer characteristics under the Eulerian coordinate. The FGD wastewater droplets are treated as a discrete phase under the Lagrangian coordinate.

The simulation calculates the flue gas flow field without the droplet injection source firstly. The standard $k-\varepsilon$ turbulent model for the flow field calculation and the SIMPLE algorithm implemented with a staggered grid method for velocity and pressure coupling are used in the simulation. The first order upwind implicit scheme is used solve the continuous phase governing equations. After a converged flow field is obtained, the atomized droplets are injected into the flow field for calculation. The effect of droplets heat and mass transfer through evaporation on the flow gas flow field and the effect of flow field changes on the droplets motion and evaporation are mutual, therefore the interphase coupling method is adapted here. Through the interaction between droplets and flue gas, the motion and particle diameter distribution of the droplets are calculated for further determination. The maximal iteration step is set as 50000 steps and the discrete droplet particles are then incorporated into the simulation. For every 10 iteration steps of the continuous flow field was calculated, the discrete atomized droplets are injected for a one iteration step calculation. The flow field is alternately calculated until the monitor parameters are converged.

In order to accurately describe the atomized droplets evaporation process, 300 parcels representing the droplet particles are set and each contains a group of droplets possessed with the identical characteristics. A random trajectory tracking method is used and 5 tries are implemented on every parcel.

\subsubsection{Experimental validation}

Based on the experiment research about single droplet with $110 \mu \mathrm{m}$ diameter suspending in the static hot air in Reference [35], the validation of numerical method is established under consistent setup with the experimental condition. The comparison of numerical results with data from [35] are shown in Figure 5, which shows that the single droplet diameter decreases over time consistently in both parts. The maximal relative error between numerical data and experimental results is within $9.8 \%$, indicating the accuracy and reliability of the established double-nozzle numerical method.

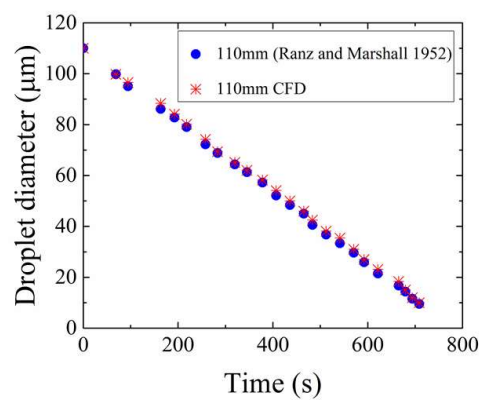

Figure 5. Comparison between numerical and experimental results on evaporation of single droplet

\section{Least-Square support vector machine model}

The basic principle of a multi-input-single-output (MISO) LSSVM prediction model is described as follows. The numerical simulation results are chosen to be the training data and the test data. For given $\mathrm{N}$ groups of training samples $\left\{x_{i}, y_{i}\right\}_{i=1}^{N}$, in which $x_{i} \in R^{n}$ is the n-dimensional input training sample, $y_{i} \in R$ is the training output sample. Before the prediction model training, the training input samples need to be normalized linearly to ensure the value range of $0-1$ and the prediction model is as followed,

$$
x_{i}^{\prime}=\frac{x_{i}-x_{i, \max }}{x_{i, \max }-x_{i, \min }}
$$


where $x_{i, \max }$ is the maximal training data and $x_{i, \min }$ is the minimal training data, $x_{i}^{\prime}$ is the pretreated data.

The optimized objective function of the MISO-LSSVM is described as followed,

$$
\begin{gathered}
\min _{\omega, b, e} J(\omega, b, e)=\frac{1}{2} \omega^{T} \omega+\gamma \frac{1}{2} \sum_{i=1}^{N} e_{i}^{2} \\
\text { s.t. } y_{i}=F\left(x_{i}\right)=\omega^{T} \varphi\left(x_{i}\right)+b+e_{i}, \quad i=1,2, \cdots, N
\end{gathered}
$$

where $J(\omega, b, e)$ is the structural risk, $\omega \in R^{n h}$ is the weight vector, $\gamma$ is the regularization parameter for control the fitting deviation in the regression function, $\varphi(\cdot): R^{n} \rightarrow R^{n h}$ is the nonlinear function to map the training sample from a low-dimensional space to a higher one, $e_{i} \in R$ is the prediction error, $b \in R$ is the deviation value.

The Gaussian radial basis function (RBF) is chosen here as the kernel function,

$$
K\left(x_{i}, x_{j}\right)=\exp \left(-\frac{\left\|x_{i}-x_{j}\right\|^{2}}{2 \sigma^{2}}\right)
$$

where $\sigma$ is the kernel function width.

The nonlinear MISO-LSSVM evaporation prediction model can be described as,

$$
y(x)=\sum_{i=1}^{N} \alpha_{i} K\left(x, x_{i}\right)+b
$$

where $\alpha_{i}$ is the support vector coefficient of the sample $\left(x_{i}, y_{i}\right)$, which is nonzero.

The average relative error (ARE) and the root-mean-square error (RMSE) are selected as the test criteria in the evaporation prediction model, where ARE and RMSE are described as,

$$
\begin{aligned}
A R E & =\frac{1}{N} \sum_{i=1}^{N}\left|\frac{y_{i}-\hat{y}_{i}}{y_{i}}\right| \times 100 \% \\
R M S E & =\sqrt{\frac{\sum_{i=1}^{N}\left(y_{i}-\hat{y}_{i}\right)^{2}}{N}} \times 100 \%
\end{aligned}
$$

where $y_{i}$ is the actual evaporation rate, $\hat{y}_{i}$ is the predicted droplet evaporation rate, $N$ is the total amount of the sample data.

\section{Results and discussion}

The properties of the flue gas and droplet particles and the settings of spray nozzles are the domain factors effecting the evaporation process. Based on the numerical model established in section 2 and by using the single control variable method, simulations are conducted on impact factors to describe the droplets evaporation rate and the diameter distribution.

\subsection{Droplet diameter evaluation}

In this study, the Sauter Mean Diameter (SMD) $\mathrm{D}_{32}$ based on the statistical average principle is chosen to describe the droplets mean diameter during the evaporation. Under the assumption that the droplet particles in the flow field are approximately possessed with the same volume and surface area, the $\mathrm{D}_{32}$ is obtained by dividing the total volume of the droplets with the total surface area. The smaller $D_{32}$ indicates the better atomization and evaporation performance and the description of $\mathrm{D}_{32}$ is as followed,

$$
D_{32}=\frac{\sum n_{i} D_{i}^{3}}{\sum n_{i} D_{i}^{2}}
$$

where $D_{i}$ is the droplet diameter and $n_{i}$ is the total amount of the droplets with diameter of $D_{i}$.

It is assumed that the FGD wastewater atomized droplets particles in this model obey the RosinRammler distribution. According to the Rosin-Rammler distribution, between the droplet diameter $d_{d}$ and the mass fraction $Y_{d}$ of droplets possessed with diameter bigger than $d_{d}$ exists an exponential relationship, which can be described as followed,

$$
Y_{d}=e^{-\left(\frac{d_{d}}{\bar{d}_{d}}\right)^{n}}
$$


where $\bar{d}_{d}$ is the droplet mean diameter, $n$ is the Rosin-Rammler distribution spread parameter.

Table 1 shows the four groups of droplets particle diameter range and the corresponding mass fraction obtained from the experimental Phase Doppler Anemometer (PDA) system. The mean diameter $\bar{d}_{d}$ equals to droplet diameter $d_{d}$ when $Y_{d}=e^{-1} \approx 0.368$. The droplet mean diameter $\bar{d}_{d}$ and the spread parameter $n$ can be obtained by fitting the values from Table 1 into Equation 23. Thus, four groups of droplet particle mean diameter and the spread parameter of the Rosin-Rammler distribution are acquired with the value of $24.79 \mu \mathrm{m}$ and $1.27708,45.08 \mu \mathrm{m}$ and 2.38151,64.05 $\mu \mathrm{m}$ and $3.23307,84.84 \mu m$ and 3.55871 , respectively.

Table 1. Four groups of droplets particle diameter range and the corresponding mass fraction distribution

\begin{tabular}{ccccc}
\hline Diameter range $d_{d}(\mu m)$ & Group 1 & Group 2 & Group 3 & Group 4 \\
\hline $0-20$ & 0.52 & 0.12 & 0.05 & 0.03 \\
\hline $20-40$ & 0.35 & 0.40 & 0.15 & 0.04 \\
\hline $40-60$ & 0.06 & 0.35 & 0.35 & 0.12 \\
\hline $60-80$ & 0.04 & 0.08 & 0.35 & 0.36 \\
\hline $80-100$ & 0.03 & 0.05 & 0.10 & 0.45 \\
\hline
\end{tabular}

\subsection{Effect of the droplets charateristics on the evaporation rate}

The evaporation performance of atomized droplets is investigated using the control single variables method under different conditions, of which the parameter values are listed in Table 2.

Table 2. The parameters values of the different conditions.

\begin{tabular}{|c|c|c|c|c|c|c|c|c|}
\hline Parameters & Case 1 & Case 2 & Case 3 & Case 4 & Case 5 & Case 6 & Case 7 & Case 8 \\
\hline Droplet velocity $(\mathrm{m} / \mathrm{s})$ & 15 & $\begin{array}{l}10,30,50 \\
70,90,110\end{array}$ & 15 & 15 & 15 & 15 & 15 & 15 \\
\hline Flue gas velocity $(\mathrm{m} / \mathrm{s})$ & 9 & 9 & 9 & $5,7,9,11,13,15$ & 9 & 9 & 9 & 9 \\
\hline Flue gas temperature $(\mathrm{K})$ & 403.15 & 403.15 & 403.15 & 403.15 & $\begin{array}{l}393.15,403.15 \\
413.15, \quad 423.15 \\
433.15\end{array}$ & 403.15 & 403.15 & 403.15 \\
\hline $\begin{array}{l}\text { Spray full cone angle of single } \\
\text { nozzle }\end{array}$ & $30^{\circ}$ & $30^{\circ}$ & $30^{\circ}$ & $30^{\circ}$ & $30^{\circ}$ & $30^{\circ}$ & $\begin{array}{l}30^{\circ}, 60^{\circ}, 90 \\
\circ, 120^{\circ}, 150\end{array}$ & 30 \\
\hline Spray nozzle of single nozzle & $0^{\circ}$ & $0^{\circ}$ & $0^{\circ}$ & $0^{\circ}$ & $0^{\circ}$ & $0^{\circ}$ & $0^{\circ}$ & $\begin{array}{l}0^{\circ}, 30^{\circ}, 45^{\circ}, 60^{\circ}, \\
90^{\circ}, 120^{\circ}, 150^{\circ}\end{array}$ \\
\hline
\end{tabular}

\subsubsection{Initial diameter of atomized droplets}

The initial mean diameter of droplet is an important parameter majorly effecting the evaporation performance. The reference case is listed in Table 2 as Case 1 . The evaporation rate and $D_{32}$ variation of droplet particles with different initial diameter of droplet are shown in Figure 6. 


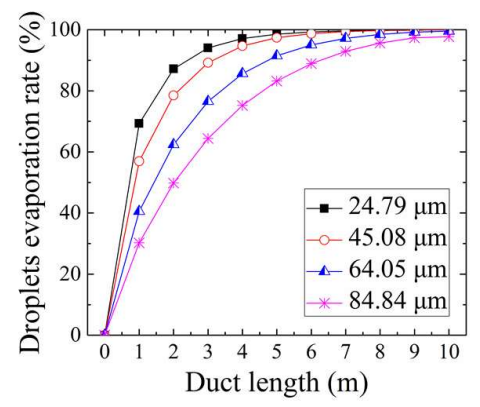

a) Droplet evaporation rate

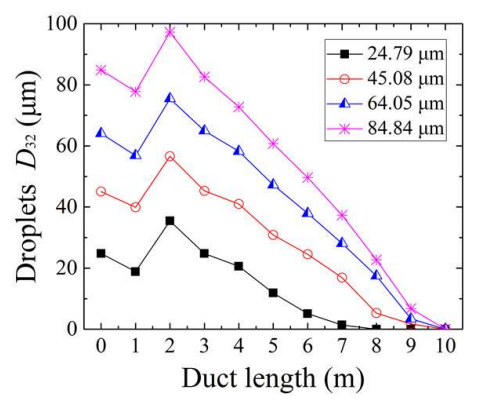

b) Variation of droplet $D_{32}$

Figure 6. Effect of the initial mean diameter of atomized droplets

It can be seen from Figure 6 a) that the atomized droplets possessed with smaller initial diameter are more likely to achieve complete evaporation with shorter time and flue duct distance. This is mainly because that the smaller droplet particles have larger specific surface area and the heat convection between droplet and flue gas is stronger in the gas-liquid two-phase flow field, contributing for the droplet to exchange heat with the flue gas and evaporate completely.

Figure $6 \mathrm{~b}$ ) shows that the variation trend of droplet mean diameter $D_{32}$ with different initial diameter is slight increasement after descent and then followed by decrement under the effect of droplets collision, breakup and coalescence. Possible explanations can be as followed, the droplet particles injected from the spray nozzle experience the first breakup then possess with higher velocity and Weber number, resulting a further breakup after droplet collision and a decrement of $D_{32}$. In the overlap and interference area of two nozzles, the droplet particles undergo intensely breakup after collision so that the descent of $D_{32}$ is more obvious around the initial atomization area. Droplet particles with smaller diameter and inertia will reach to the flue gas velocity rapidly and be carried into the flow field. The Weber number of droplet particles then increase and the coalescence effect after collision is dominant, thus the droplet $D_{32}$ increases. With the evaporation proceeds, the droplet particles absorb the flue gas heat and the droplet $D_{32}$ gradually decrease, achieving a complete evaporation within the flue duct length of $10 \mathrm{~m}$.

The droplet injected from the spray nozzles experience collision and coalescence near the point of $x=1 \mathrm{~m}$ along the flow direction and the coalescence effect is more concentrated and intense within the distance range of $x=1-3 \mathrm{~m}$. The maximal atomized droplet diameter after coalescence with the initial mean diameter of $d_{d}=24.79 \mu \mathrm{m}, 45.08 \mu \mathrm{m}, 64.05 \mu \mathrm{m}, 84.84 \mu \mathrm{m}$ are $d_{d, \max }=41.85 \mu \mathrm{m}, 87.14$ $\mu m, 119.47 \mu m, 143.29 \mu m$, respectively. The droplet particle diameter distribution at point of $x=1.5$ $\mathrm{m}, 5.5 \mathrm{~m}, 9.5 \mathrm{~m}$ along the flow direction are shown in Figure 7 with initial mean diameter of $d_{d}$ $=84.84 \mu \mathrm{m}$.

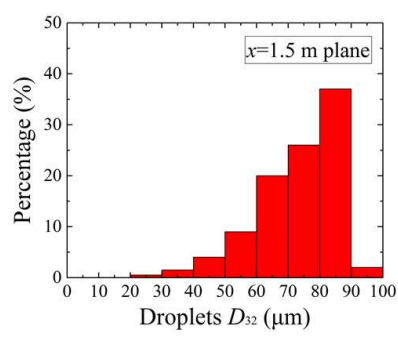

a) $x=1.5 \mathrm{~m}$

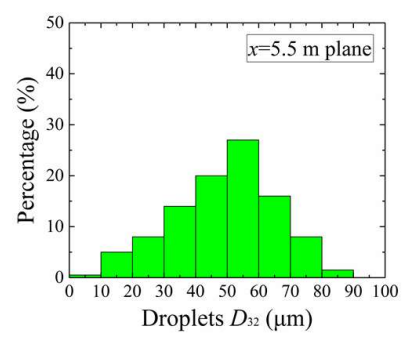

b) $x=5.5 \mathrm{~m}$

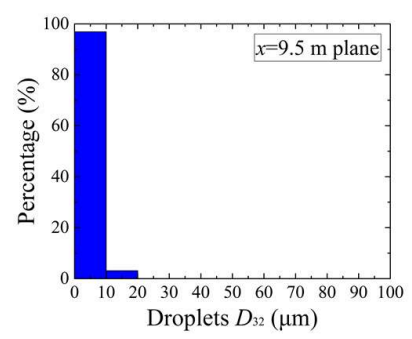

c) $x=9.5 \mathrm{~m}$

Figure 7. The droplet diameter distribution at different cross-section of the flue duct $\left(d_{d}=\right.$ $84.84 \mu \mathrm{m})$

Figure 7 shows that at $x=1.5 \mathrm{~m}$ along the flow direction the droplet particles mainly undergo collision and form into particles with larger diameter. The percentage of droplet particles with diameter range of $d_{d}=60-70 \mu \mathrm{m}, 70-80 \mu \mathrm{m}, 80-90 \mu \mathrm{m}$ are $19.98 \%, 26.12 \%$ and $37.33 \%$, respectively. 
At $x=5.5 \mathrm{~m}$, the droplet particles absorb heat from flue gas and evaporate, resulting the percentage of droplet particles with diameter range of $d_{d}=40-50 \mu \mathrm{m}, 50-60 \mu \mathrm{m}, 60-70 \mu \mathrm{m}$ to $20.02 \%, 27.10 \%$ and 15.96, respectively. At $x=9.5 \mathrm{~m}$, the atomized droplets approximately achieve complete evaporation and the percentage of droplet particles with diameter range of $d_{d}=0-10 \mu \mathrm{m}, 10-20 \mu \mathrm{m}$ are $96.91 \%$ and $3.19 \%$, indicating that only few droplets with smaller diameter are residual.

\subsubsection{Initial velocity of atomized droplets}

The reference case on effect of atomized droplet initial velocity on the evaporation rate is listed in Table 2 as Case 2. Figure 8 is the evaporation rate and $D_{32}$ variation of droplet particles with different initial droplet velocity.

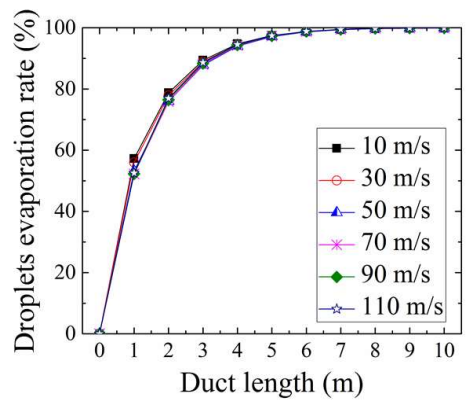

a) Droplet evaporation rate

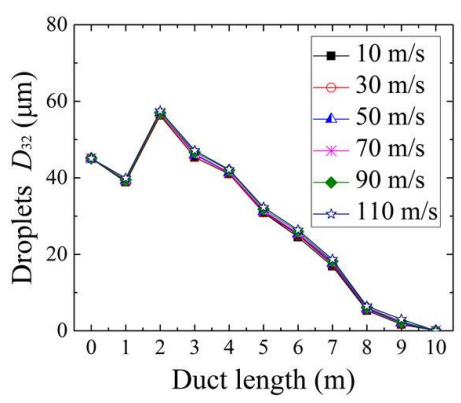

b) Variation of droplet $D_{32}$

Figure 8. Effect of the initial velocity of atomized droplets

Figure 8 a) indicates that the atomized droplets evaporation rate decreases as the initial droplets velocity increase under the identical flue gas temperature. This is primarily because that the atomized droplets undergo a series of shape formation and the velocity differs among droplet particles with different diameter. The residence time of droplet particle is the key parameter effecting the evaporation rate. The excessive increment on the initial droplet velocity will enlarge the spray conical surface area at the initial atomization and enhance the droplet dispersion. However, under the double-nozzle arrangement, higher droplet initial velocity may increase the interference area between nozzles and the probability of droplet coalescence, resulting the descent of evaporation rate. Droplet particles with relatively small initial velocity tend to have longer residence time in the flue duct and fully exchange heat with flue gas. Figure $8 \mathrm{~b}$ ) illustrates the same tendency of droplets $D_{32}$ along the flow direction under different initial velocity with section 4.2.1, which is increment after descent and then gradual decrement. Possible explanations can be seen in section 4.2.1.

The maximal droplet particle diameter with the initial droplet velocity of $u_{d}=10 \mathrm{~m} / \mathrm{s}, 30 \mathrm{~m} / \mathrm{s}$, $50 \mathrm{~m} / \mathrm{s}, 70 \mathrm{~m} / \mathrm{s}, 90 \mathrm{~m} / \mathrm{s}$ and $110 \mathrm{~m} / \mathrm{s}$ are $d_{d, \max }=85.86 \mu \mathrm{m}, 86.53 \mu \mathrm{m}, 86.98 \mu \mathrm{m}, 87.52 \mu \mathrm{m}, 87.90 \mu \mathrm{m}$, $88.39 \mu \mathrm{m}$, respectively. The droplet particle diameter distribution at point of $x=1.5 \mathrm{~m}, 5.5 \mathrm{~m}, 9.5 \mathrm{~m}$ along the flow direction are presented in Figure 9 with the initial droplet velocity of $u_{d}=10 \mathrm{~m} / \mathrm{s}$.

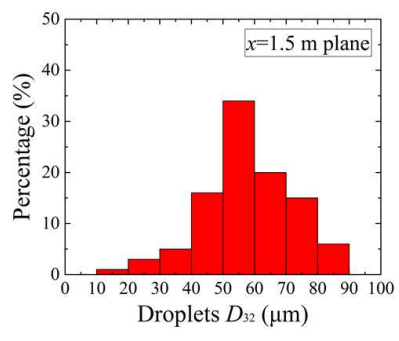

a) $x=1.5 \mathrm{~m}$

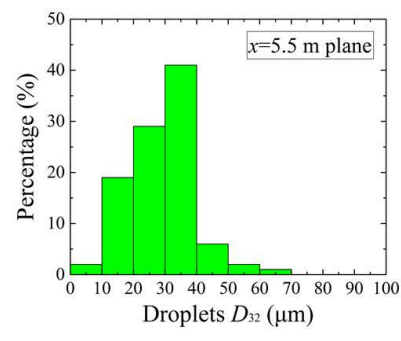

b) $x=5.5 \mathrm{~m}$

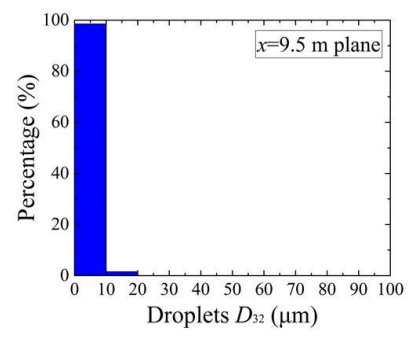

c) $x=9.5 \mathrm{~m}$

Figure 9. The droplet diameter distribution at different cross-section of the flue duct $\left(u_{d}=10 \mathrm{~m} / \mathrm{s}\right)$

It can be seen from Figure 9 that the percentage of droplet particles with diameter range of $d_{d}$ $=40-50 \mu \mathrm{m}, 50-60 \mu \mathrm{m}, 60-70 \mu \mathrm{m}$ are $16.30 \%, 34.01 \%$ and $20.23 \%$, respectively at $x=1.5 \mathrm{~m}$ along the 
flow direction. At $x=5.5 \mathrm{~m}$, the droplet particles continue to absorb heat and evaporate and the percentage of particles with diameter range of $d_{d}=10-20 \mu \mathrm{m}, 20-30 \mu \mathrm{m}, 30-40 \mu \mathrm{m}$ are 19.20\%, 28.97\% and $41.11 \%$, respectively. At $x=9.5 \mathrm{~m}$, the percentage of droplet particles with diameter of $d_{d}=0$ $10 \mu \mathrm{m}, 10-20 \mu \mathrm{m}$ are $98.51 \%$ and $1.49 \%$, indicating that the vast majority of droplet particles are fully evaporated.

Figure 10 is the droplet velocity distribution in the double-nozzle condition. According to the distribution, the droplet velocity reaches the maximum near the spray nozzles and significantly reduces along the flow direction, then the droplet particles are entrained by flue gas rapidly into the flow field until achieve complete evaporation.

To sum up, the initial droplet velocity will impact the evaporation rate on a certain level but the effect can be ignored. With the spray nozzles maintaining the same range of diameter, increasing the initial injection velocity of droplet benefits the atomization performance. Thus, proper option of the type of spray nozzles and increment of initial injection velocity of droplet will ensure a better atomization and evaporation rate.

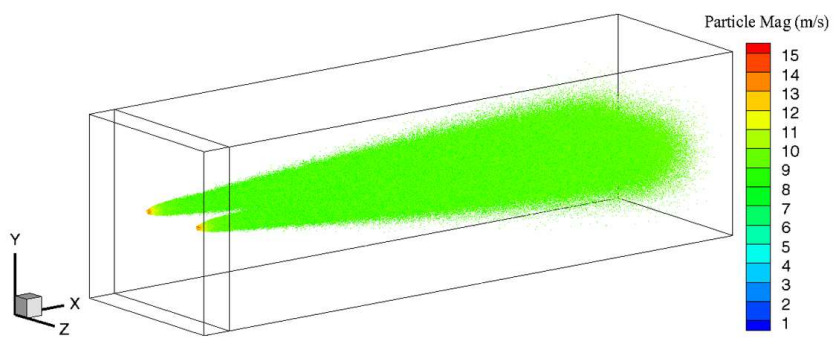

Figure 10. The atomized droplet velocity distribution field

\subsubsection{Initial temperature of atomized droplets}

The reference case on effect of droplet initial temperature on the evaporation rate is listed in Table 2 as Case 3. Figure 11 is the evaporation rate and $D_{32}$ variation of droplet particles along the flue duct.

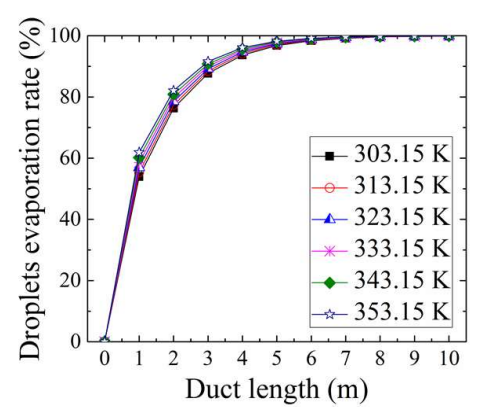

a) Droplet evaporation rate

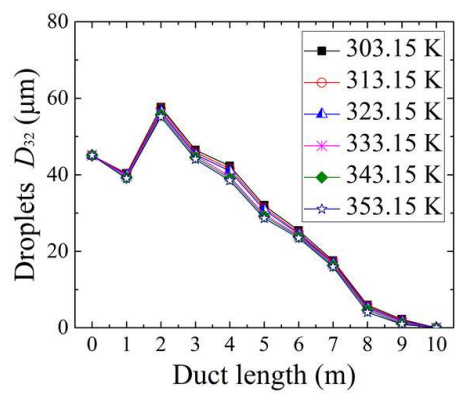

b) Variation of droplet $D_{32}$

Figure 11. Effect of the initial temperature of atomized droplets

As shown in Figure 11 a), with the greater initial droplet temperature comes the better evaporation rate and the shorter distance required for the complete evaporation. One of the possible reasons for this is that the droplet particles experience a more intensive rotational flow injected from spray nozzles with the smaller surface tension and viscosity because of the relatively high initial temperature. The improved second breakup effect makes the droplet atomized into fine particles and easier to evaporate. Figure $11 \mathrm{~b}$ ) indicates that the droplet $D_{32}$ along the flue duct length with different initial droplet temperature shows the same trend with conditions in section 4.2.1 and 4.2.2. Possible explanations can be seen in section 4.2.1.

The maximal droplet particle diameter after collision and coalescence with the initial droplet temperature of $T_{d}=303.15 \mathrm{~K}, 313.15 \mathrm{~K}, 323.15 \mathrm{~K}, 333.15 \mathrm{~K}, 343.15 \mathrm{~K}$ and $353.15 \mathrm{~K}$ are $d_{d, \max }=89.01$ 
$\mu m, 88.53 \mu m, 87.14 \mu m, 86.34 \mu m, 85.72 \mu m, 84.88 \mu m$, respectively. The droplet particle diameter distribution at point of $x=1.5 \mathrm{~m}, 5.5 \mathrm{~m}, 9.5 \mathrm{~m}$ along the flow direction are presented in Figure 12 with the initial droplet temperature of $T_{d}=353.15 \mathrm{~K}$, from which it can be seen that the percentage of droplet particles with diameter range of $d_{d}=50-60 \mu \mathrm{m}, 60-70 \mu \mathrm{m}, 70-80 \mu \mathrm{m}$ are $42.86 \%, 18.75 \%$ and $13.56 \%$, respectively at $x=1.5 \mathrm{~m}$. At $x=5.5 \mathrm{~m}$, the droplet particles continue to evaporate and the percentage of particles with diameter range of $d_{d}=10-20 \mu \mathrm{m}, 20-30 \mu \mathrm{m}, 30-40 \mu \mathrm{m}$ are 17.32\%, $30.12 \%$ and $40.05 \%$, respectively. At $x=9.5 \mathrm{~m}$, the percentage of droplet particles with diameter of $d_{d}=0-10 \mu m, 10-20 \mu m$ are $98.30 \%$ and $1.70 \%$.

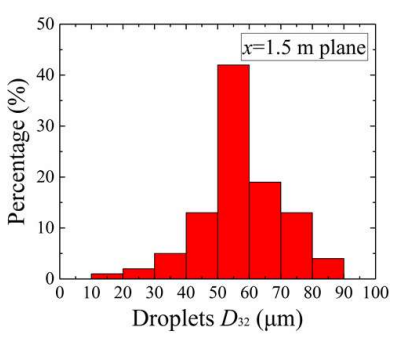

a) $x=1.5 \mathrm{~m}$

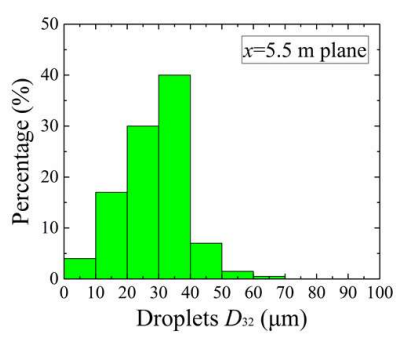

b) $x=5.5 \mathrm{~m}$

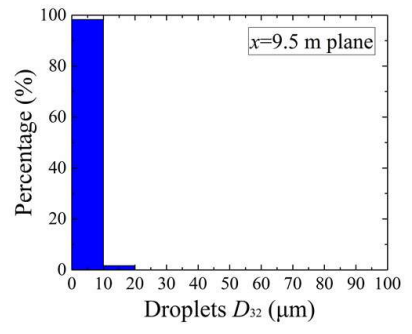

c) $x=9.5 \mathrm{~m}$

Figure 12. The droplet diameter distribution at different cross-section of the flue duct $\left(T_{d}=\right.$ $353.15 K)$

\subsubsection{Velocity of flue gas}

The reference case on effect of flue gas velocity on the evaporation rate is listed in Table 2 as Case 4 . Figure 13 is the evaporation rate and $D_{32}$ variation of droplet particles under different flue gas velocity.

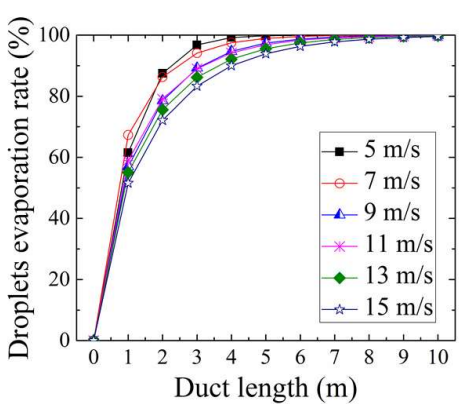

a) Droplet evaporation rate

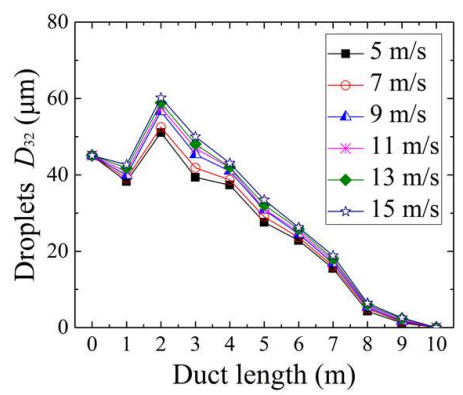

b) Variation of droplet $D_{32}$

Figure 13. Effect of the flue gas velocity

According to Figure 13 a), the droplet evaporation rate decreases with the increment of flue gas velocity, indicating that the residence time of droplet particle in the flue duct is one of the important impact factors on the evaporation rate. With the relatively large flue gas velocity, droplet particles with small diameter and inertance will be carried into the flow field in a short time. The heat convection between droplet particles and flue gas is deteriorated, leading to the descent of total quantity of heat exchange in the liquid-gas two-phase flow. The residence time of droplet particles in the flue duct is shortened, resulting an insufficient heat exchange and a descent of droplet evaporation rate. Figure $13 \mathrm{~b}$ ) shows the same $D_{32}$ variation tendency under different flue gas velocity with section 4.2 .1 , which is a drop followed by slight increment and then decrement along the flue duct length. Possible explanations can be seen in section 4.2.1.

The droplet injected from the spray nozzles experience collision and coalescence at $x=1 \mathrm{~m}$ along the flow direction and the coalescence effect is more concentrated and intense within the distance range of $x=1-3 \mathrm{~m}$. The maximal atomized droplet diameter with the flue gas velocity of $u_{f}$ $=5 \mathrm{~m} / \mathrm{s}, 7 \mathrm{~m} / \mathrm{s}, 9 \mathrm{~m} / \mathrm{s}, 11 \mathrm{~m} / \mathrm{s}, 13 \mathrm{~m} / \mathrm{s}$ and $15 \mathrm{~m} / \mathrm{s}$ are $d_{d, \max }=84.22 \mu \mathrm{m}, 86.41 \mu \mathrm{m}, 87.14 \mu \mathrm{m}, 88.34 \mu \mathrm{m}$, $88.78 \mu \mathrm{m}$ and $89.08 \mu \mathrm{m}$, respectively. The droplet particle diameter distribution at point of $x=1.5$ 
$\mathrm{m}, 5.5 \mathrm{~m}, 9.5 \mathrm{~m}$ along the flow direction are shown in Figure 14 under the condition of flue gas velocity $u_{f}=5 \mathrm{~m} / \mathrm{s}$.

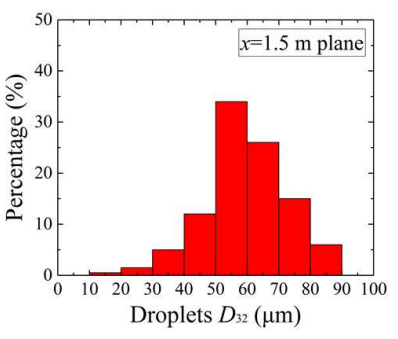

a) $x=1.5 \mathrm{~m}$

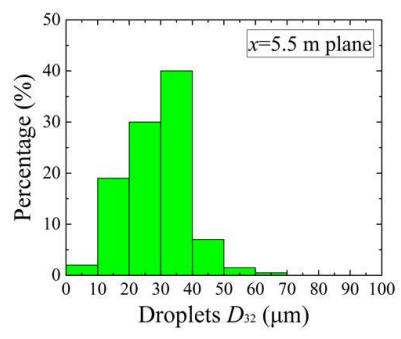

b) $x=5.5 \mathrm{~m}$

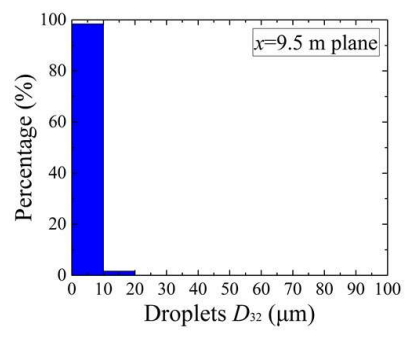

c) $x=9.5 \mathrm{~m}$

Figure 14. The droplet diameter distribution at different cross-section of the flue duct $\left(u_{f}=5 \mathrm{~m} / \mathrm{s}\right)$

Figure 14 shows that the percentage of droplet particles with diameter range of $d_{d}=50-60 \mu \mathrm{m}$, $60-70 \mu \mathrm{m}, 70-80 \mu \mathrm{m}$ are $34.21 \%, 25.88 \%$ and $15.01 \%$, respectively at $x=1.5 \mathrm{~m}$ along the flow direction. At $x=5.5 \mathrm{~m}$, the droplet particles continue to absorb heat and evaporate and the percentage of particles with diameter range of $d_{d}=10-20 \mu \mathrm{m}, 20-30 \mu \mathrm{m}, 30-40 \mu \mathrm{m}$ are 19.22\%, 30.42\% and $40.18 \%$, respectively. At $x=9.5 \mathrm{~m}$, the percentage of droplet particles with diameter of $d_{d}=0$ $10 \mu \mathrm{m}, 10-20 \mu \mathrm{m}$ are $98.40 \%$ and $1.60 \%$.

\subsubsection{Temperature of flue gas}

The reference case on effect of flue gas temperature on the evaporation rate is listed in Table 2 as Case 5. Figure 15 shows the droplet evaporation rate and $D_{32}$ variation of droplet particles with different conditions.

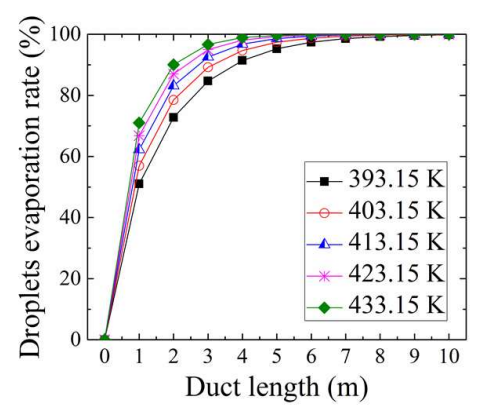

a) Droplet evaporation rate

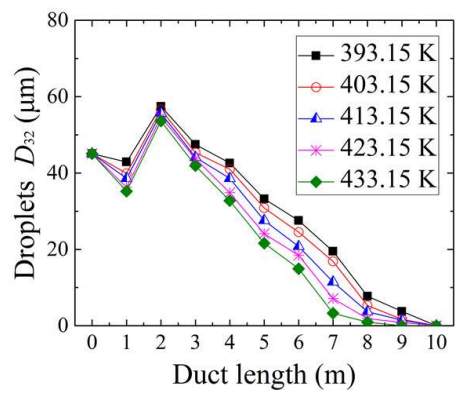

b) Variation of droplet $D_{32}$

Figure 15. Effect of the flue gas temperature

Figure 15 a) demonstrated that the same trend of droplet evaporation rate under different flue gas temperature with section 4.2.3 are found, which is higher flue gas temperature comes with greater evaporation rate. As the detail shown in section 4.2.3, possible reason of this regularity is that the increment of flue gas temperature brings up the temperature difference between flue gas and droplet particles, therefore the intensive heat exchange between the liquid-gas two-phase flow is enhanced and so is the evaporation performance. Figure $15 \mathrm{~b}$ ) shows that the droplet $D_{32}$ under different flue gas temperature exhibits the same tendency with detail in section 4.2.1, which is slight descent followed by increment and then gradual decrement. It is concluded from the aforementioned sections that the breakup after collision near the initial atomization area, the coalescence after collision around the fully developed flow field and final complete evaporation are the main reasons of this $D_{32}$ variation tendency.

The maximal droplet particle diameter with the initial flue gas temperature of $T_{f}=393.15 \mathrm{~K}$, $403.15 \mathrm{~K}, 413.15 \mathrm{~K}, 423.15 \mathrm{~K}, 433.15 \mathrm{~K}$ are $d_{d, \max }=93.89 \mu m, 87.14 \mu m, 81.88 \mu m, 76.97 \mu m, 70.32$ $\mu \mathrm{m}$, respectively. The droplet particle diameter distribution at point of $x=1.5 \mathrm{~m}, 5.5 \mathrm{~m}, 9.5 \mathrm{~m}$ along the flow direction with flue gas temperature of $T_{f}=433.15 \mathrm{~K}$ are presented in Figure 16 . It can be 
seen from Figure 16 that the percentage of droplet particles with diameter range of $d_{d}=20-30 \mu m$, 30-40 $\mu \mathrm{m}, 40-50 \mu \mathrm{m}$ are $18.30 \%, 42.10 \%$ and $27.43 \%$, respectively at $x=1.5 \mathrm{~m}$. At $x=5.5 \mathrm{~m}$, the percentage of particles with diameter range of $d_{d}=10-20 \mu \mathrm{m}, 20-30 \mu \mathrm{m}, 30-40 \mu \mathrm{m}$ are $22.31 \%, 41.05 \%$ and $17.13 \%$, respectively. At $x=9.5 \mathrm{~m}$, the percentage of droplet particles with diameter of $d_{d}=0$ $10 \mu \mathrm{m}, 10-20 \mu \mathrm{m}$ are $99.41 \%$ and $0.59 \%$, indicating that the vast majority of droplet particles are fully evaporated。

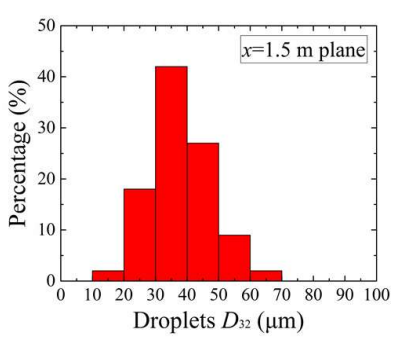

a) $x=1.5 \mathrm{~m}$

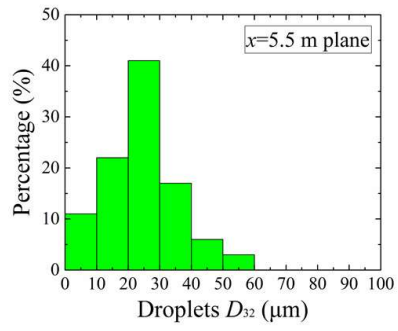

b) $x=5.5 \mathrm{~m}$

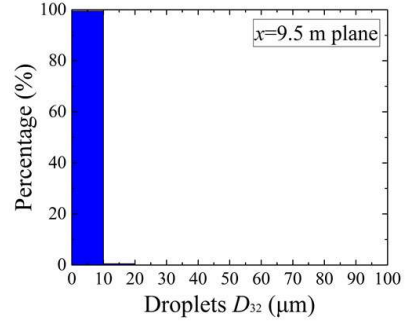

c) $x=9.5 \mathrm{~m}$

Figure 16. The droplet diameter distribution at different cross-section of the flue duct $\left(T_{f}=\right.$ $393.15 K)$

\subsubsection{Flow rate of single spray nozzle}

The reference case on effect of flow rate of single nozzle on the evaporation rate is listed in Table 2 as Case 6. The evaporation rate and $D_{32}$ variation of droplet particles are shown in Figure 17.

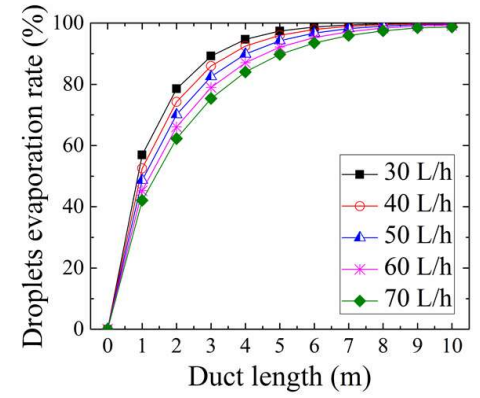

a) Droplet evaporation rate

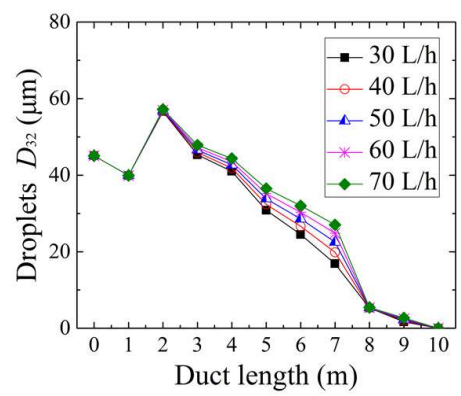

b) Variation of droplet $D_{32}$

Figure 17. Effect of the flow rate of single spray nozzle

It can be seen from Figure 17 a) that the droplet evaporation rate decreases with the increment of single nozzle flow rate. This is primarily because the total quantity of droplet particles will increase and result in the uneven droplet dispersion so that the droplet particles cannot fully contact and absorb heat from flue gas. Moreover, when the flow rate of single nozzle exceeds $70 \mathrm{~L} / \mathrm{h}$, due to the uneven dispersion of droplet and insufficient heat from flue gas, the incomplete droplet evaporation within the flue duct length of $10 \mathrm{~m}$ happens, which means that the distance needed to achieve complete evaporation is required to be enlarged. The result indicates that with the sufficient area of flue duct, an improved multi-nozzle arrangement with small flow rate is recommended to ensure the better evaporation rate. Figure $17 \mathrm{~b}$ ) shows the same $D_{32}$ variation under different flow rate of single nozzle with detail illustrated in section 4.2.1 and possible reasons are also shown in that section.

The droplet injected from the spray nozzles experience collision and coalescence at $x=1 \mathrm{~m}$ along the flow direction and the coalescence effect is more intense within the distance range of $x=1$ $3 \mathrm{~m}$. The maximal atomized droplet diameter with the single nozzle flow rate of $L_{n}=30 \mathrm{~L} / \mathrm{h}, 40 \mathrm{~L} / \mathrm{h}$, $50 \mathrm{~L} / \mathrm{h}, 60 \mathrm{~L} / \mathrm{h}$ and $70 \mathrm{~L} / \mathrm{h}$ are $d_{d, \max }=87.14 \mu \mathrm{m}, 87.65 \mu \mathrm{m}, 88.23 \mu \mathrm{m}, 88.74 \mu \mathrm{m}, 89.32 \mu \mathrm{m}$ and 90.18 $\mu \mathrm{m}$, respectively. The droplet particle diameter distribution at point of $x=1.5 \mathrm{~m}, 5.5 \mathrm{~m}, 9.5 \mathrm{~m}$ along the flow direction are shown in Figure 18 under the condition of single flow rate $L_{n}=70 \mathrm{~L} / \mathrm{h}$. 


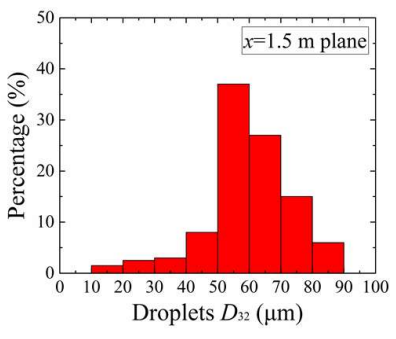

a) $x=1.5 \mathrm{~m}$

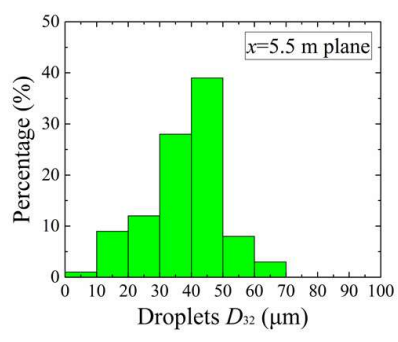

b) $x=5.5 \mathrm{~m}$

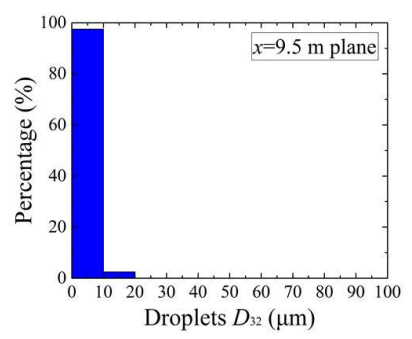

c) $x=9.5 \mathrm{~m}$

Figure 18. The droplet diameter distribution at different cross-section of the flue duct $\left(L_{n}=70 \mathrm{~L} / \mathrm{h}\right)$

It can be seen from Figure 18 that the percentage of droplet particles with diameter range of $d_{d}$ $=50-60 \mu \mathrm{m}, 60-70 \mu \mathrm{m}, 70-80 \mu \mathrm{m}$ are $37.84 \%, 27.51 \%$ and $15.62 \%$, respectively at $x=1.5 \mathrm{~m}$. At $x=5.5$ $\mathrm{m}$, the droplet particles continue to absorb heat and evaporate and the percentage of particles with diameter range of $d_{d}=20-30 \mu \mathrm{m}, 30-40 \mu \mathrm{m}, 40-50 \mu \mathrm{m}$ are $12.00 \%, 28.51 \%$ and $39.30 \%$, respectively. At $x=9.5 \mathrm{~m}$, the percentage of droplet particles with diameter of $d_{d}=0-10 \mu \mathrm{m}, 10-20 \mu \mathrm{m}$ are $97.52 \%$ and $2.48 \%$.

\subsubsection{Spray full cone angle of nozzles}

The reference case on effect of spray full cone angle of single nozzle is listed in Table 2 as Case 7. Figure 19 shows the atomized droplet evaporation rate and $D_{32}$ variation of droplet particles with different conditions.

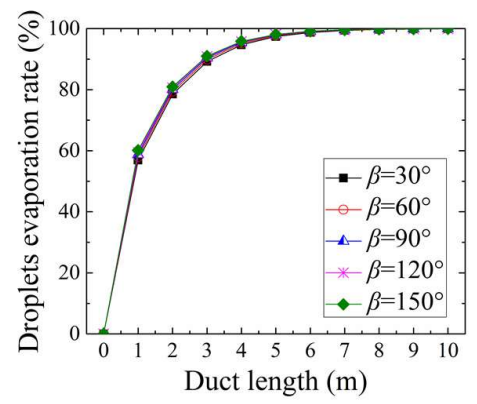

a) Droplet evaporation rate

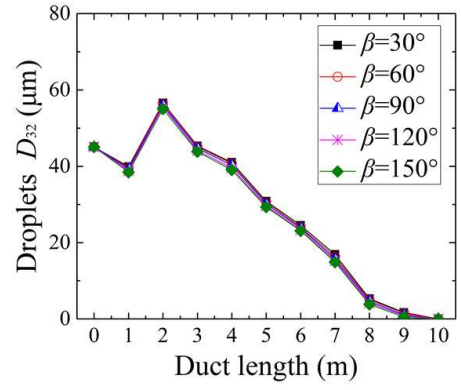

b) Variation of droplet $D_{32}$

Figure 19. Effect of the spray full cone angle of single nozzle

Figure 19 a) shows that the droplet evaporation rate is upward but subtle as the spray full cone angle of single nozzle increases. Theoretically, the increment of spray full cone angle in single nozzle will help to form a greater conical spray area for the droplet particles to fully disperse in the flow field. Nevertheless, with the present characteristics of flue gas and flow rate of single nozzle, the heat source provided by the flow field is sufficient so that the increment of spray full cone angle does not put an obvious impact on the evaporation rate. Thus, the selection of nozzle spray full cone angle on the nozzles arrangement only need to ensure the atomized droplet does not contact with the flue duct wall in the practical conditions. Figure $19 \mathrm{~b}$ ) shows the $D_{32}$ variation trend similar with detail illustrated in section 4.2.1 and possible reasons are detailed in that section.

The maximal droplet particle diameter with the full cone angle of single nozzle $\beta=30^{\circ}, 60^{\circ}, 90^{\circ}$, $120^{\circ}, 150^{\circ}$ are $d_{d, \max }=87.14 \mu \mathrm{m}, 87.02 \mu \mathrm{m}, 86.91 \mu \mathrm{m}, 86.64 \mu \mathrm{m}, 86.23 \mu \mathrm{m}$, respectively. The droplet particle diameter distribution at point of $x=1.5 \mathrm{~m}, 5.5 \mathrm{~m}, 9.5 \mathrm{~m}$ along the flow direction are presented in Figure 20 with the full cone angle of single nozzle $\beta=150^{\circ}$, from which it can be seen that the percentage of droplet particles with diameter range of $d_{d}=50-60 \mu \mathrm{m}, 60-70 \mu \mathrm{m}, 70-80 \mu \mathrm{m}$ are $36.78 \%, 22.00 \%$ and $16.34 \%$, respectively at $x=1.5 \mathrm{~m}$. At $x=5.5 \mathrm{~m}$, the droplet particles continue to evaporate and the percentage of particles with diameter range of $d_{d}=10-20 \mu \mathrm{m}, 20-30 \mu \mathrm{m}, 30-40$ 
$\mu \mathrm{m}$ are $16.20 \%, 26.71 \%$ and $41.41 \%$, respectively. At $x=9.5 \mathrm{~m}$, the percentage of droplet particles with diameter of $d_{d}=0-10 \mu m, 10-20 \mu m$ are $98.19 \%$ and $1.81 \%$.

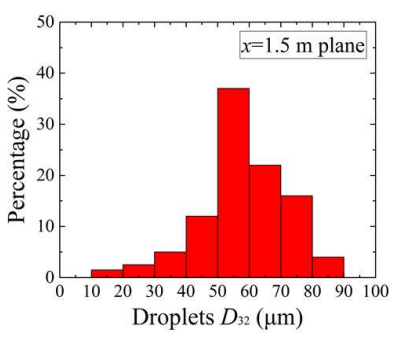

a) $x=1.5 \mathrm{~m}$

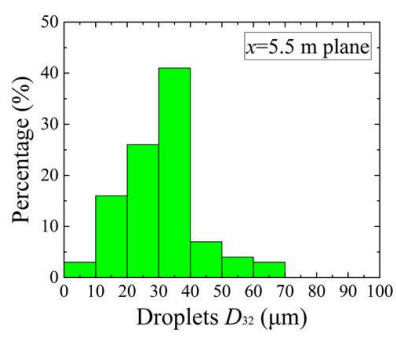

b) $x=5.5 \mathrm{~m}$

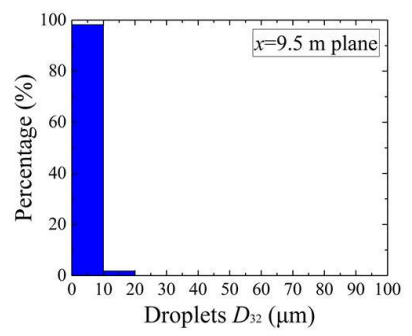

c) $x=9.5 \mathrm{~m}$

Figure 20. The droplet diameter distribution at different cross-section of the flue duct $\left(\beta=150^{\circ}\right)$

\subsubsection{Spray direction of single nozzle}

The reference case on effect of nozzle spray direction on the evaporation rate is listed in Table 2 as Case 8. Figure 21 is the droplet evaporation rate and $D_{32}$ variation of droplet particles under different spray direction.

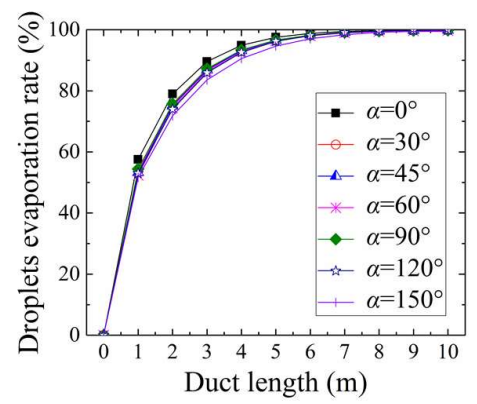

a) Droplet evaporation rate

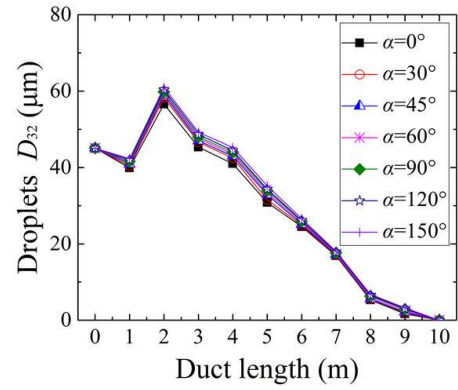

b) Variation of droplet $D_{32}$

Figure 21. Effect of the spray direction of single nozzle

Figure 21 a) illustrates that the evaporation rate of droplet particles reaches the highest value with the spray direction parallel with the flow direction, meanwhile the evaporation performance is weakened with the increment of angle. Theoretically, the droplet particles residence time and relative motion between droplet and flue gas will be strengthened with the increment of the above-mentioned angle, leading to the promoted heat transfer between droplet and flue gas. However, the spatial distribution of droplet particles is determined by the spray direction of nozzle, which means that with the wider spray direction of nozzle comes the worse droplet diffusion at the initial atomization area, resulting the insufficient heat exchange between droplet particles and flue gas and the evaporation rate is reduced. Figure $21 \mathrm{~b}$ ) shows the same $D_{32}$ variation under different spray direction of single nozzle with detail illustrated in section 4.2.1 and possible reasons are also shown in that section.

The temperature nephograms of flue gas at different cross-section under different nozzle spray direction are shown in Figure 22. It can be concluded from these figures that adding the angle between droplets spray direction and flue gas flow direction leads to an uneven diffused droplet situation in the flow field. The overlap and interference area are increased between the two nozzles and the evaporation performance is weakened due to the increased droplet spray angle. 


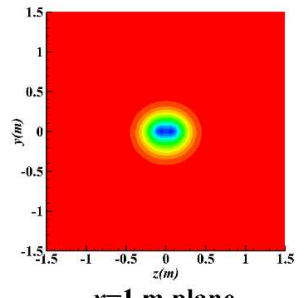

$x=1 \mathrm{~m}$ plane

a) $\alpha=0^{\circ}$

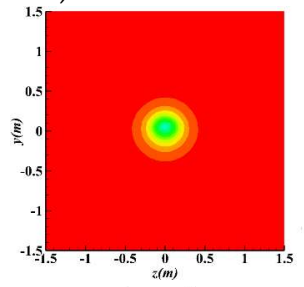

$x=1 \mathrm{~m}$ plane

b) $\alpha=45^{\circ}$

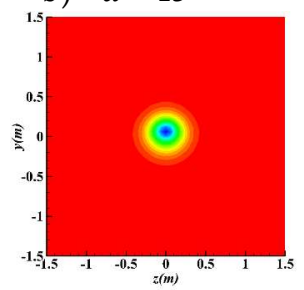

$x=1 \mathrm{~m}$ plane

c) $\alpha=90^{\circ}$

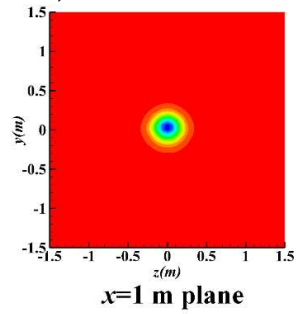

d) $\alpha=150^{\circ}$

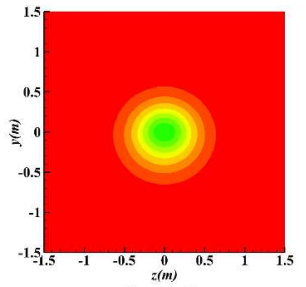

$x=3 \mathrm{~m}$ plane

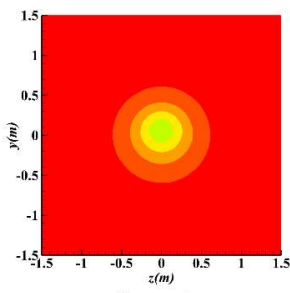

$x=3 \mathrm{~m}$ plane

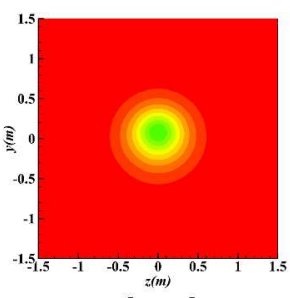

$x=3 \mathrm{~m}$ plane
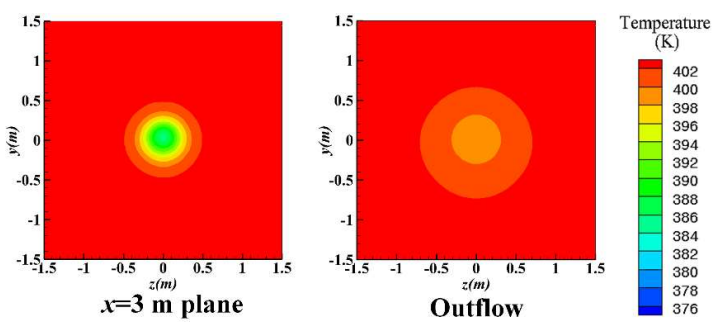

Figure 22. The flue gas temperature nephogram at different cross-section with different spray direction

The maximal droplet particle diameter with the spray direction of single nozzle $\alpha=0^{\circ}, 30^{\circ}, 45^{\circ}$, $60^{\circ}, 90^{\circ}, 120^{\circ}$ and $150^{\circ}$ are $d_{d, \max }=87.14 \mu \mathrm{m}, 87.44 \mu \mathrm{m}, 87.87 \mu \mathrm{m}, 88.11 \mu \mathrm{m}, 88.52 \mu \mathrm{m}, 88.98 \mu \mathrm{m}$, $89.28 \mu \mathrm{m}$, respectively. The droplet particle diameter distribution at point of $x=1.5 \mathrm{~m}, 5.5 \mathrm{~m}, 9.5 \mathrm{~m}$ along the flow direction are presented in Figure 23 with the spray direction of single nozzle $\alpha=90^{\circ}$, from which it can be seen that the percentage of droplet particles with diameter range of $d_{d}=50-60$ $\mu \mathrm{m}, 60-70 \mu \mathrm{m}, 70-80 \mu \mathrm{m}$ are $36.10 \%, 24.23 \%$ and $17.17 \%$, respectively at $x=1.5 \mathrm{~m}$. At $x=5.5 \mathrm{~m}$, the droplet particles continue to evaporate and the percentage of particles with diameter range of $d_{d}$ $=10-20 \mu \mathrm{m}, 20-30 \mu \mathrm{m}, 30-40 \mu \mathrm{m}$ are $17.30 \%, 28.14 \%$ and $38.11 \%$, respectively. At $x=9.5 \mathrm{~m}$, the percentage of droplet particles with diameter of $d_{d}=0-10 \mu \mathrm{m}, 10-20 \mu \mathrm{m}$ are $97.00 \%$ and $3.00 \%$. 


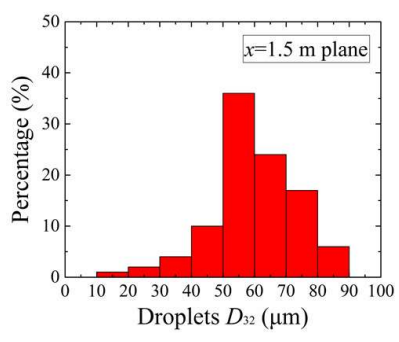

a) $x=1.5 \mathrm{~m}$

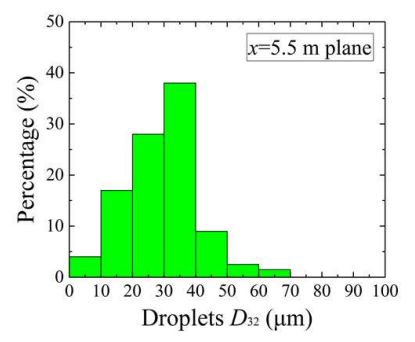

b) $x=5.5 \mathrm{~m}$

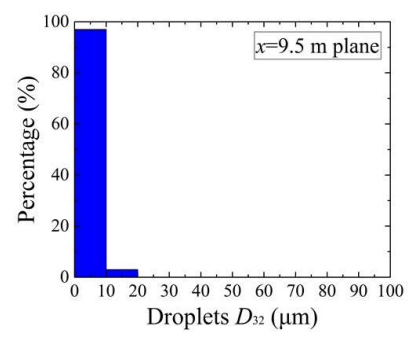

c) $x=9.5 \mathrm{~m}$

Figure 23. The droplet diameter distribution at different cross-section of the flue duct $\left(\alpha=90^{\circ}\right)$

\subsection{The LSSVM prediction of droplet evaporation performance}

Based on the above numerical simulations and to provide a comprehensive understanding of the influencing factors on FGD wastewater spray evaporation treatment, a MISO-LSSVM prediction model is built to optimize the spray nozzle selection and arrangement in the practical application scenario.

To validate the MISO-LSSVM evaporation prediction model, nine variables, including the atomized droplet initial mean diameter, initial velocity and temperature, the flue gas velocity and temperature, the flow rate of single nozzle, the spray full cone angle, the spray direction and the evaporation distance, are selected as the input, meanwhile the evaporation rates at different crosssection along the flue duct under various conditions as the output. A set of 1600 groups of numerical data are chosen to be the prediction model sample, in which 1200 groups of data are training data and 400 groups are testing data.

In the first step, 1200 groups of training data are selected to rolling train the LSSVM model for predicting the evaporation rate, cross validating the prediction model parameters and balancing the training accuracy. The optimization parameters are set to ensure the minimal root-mean-square error with $\gamma=10000$ and $\sigma=0.01$. Then the aforementioned nine variables and the corresponding conditions are processed into the model for the output prediction and the results are shown in Figure 24.

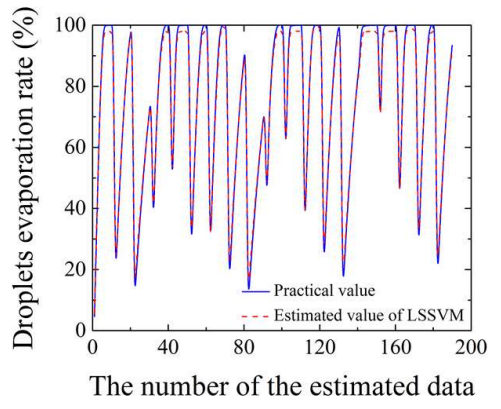

a) Fitting degree between the predicted and practical value

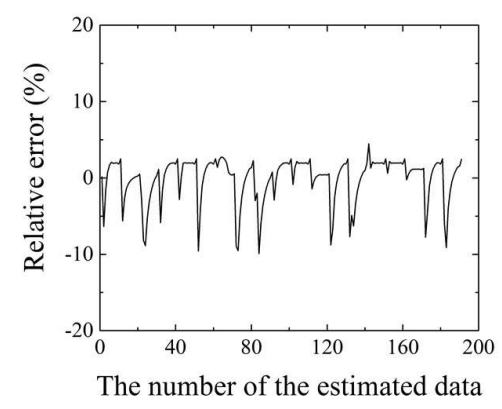

b) Average relative error

Figure 24. Accuracy of the MISO-LSSVM model

Figure 24 a) demonstrates the fitting degree between the numerical value and the predicted value of the evaporation MISO-LSSVM model, indicating a good fit for predicting the evaporation rate at different cross-section in the above-mentioned conditions. Figure $24 \mathrm{~b}$ ) is the average relative error (ARE) between the numerical and predicted value in the MISO-LSSVM model, in which the maximal relative error is within $9 \%$, the ARE is $2.1558 \%$ and the root-mean-square error (RMSE) is $1.6440 \%$. It is concluded that the MISO-LSSVM prediction model with nine input variables and one output variables is suitable to accurately predict the atomized droplet evaporation rate at different cross-section of flue duct under various conditions and the interpolation performance is good. Thus, the prediction model can be utilized in the optimization of nozzles selection and arrangement in the 
FGD wastewater spray evaporation system, as well as the parameter setting and technical control in the practical application.

\section{Conclusion}

The present study investigates several key elements effecting the evaporation performance of FGD wastewater spray technology, such as the characteristics of atomized droplet and flue gas and the settings of spray nozzles. The numerical simulation was established under the EulerianLagrangian approach with different operate conditions. The MISO-LSSVM model is used to predict the evaporation rate with multiple factors based on the numerical results. The following conclusions are made.

1) The nozzles flow rate setting is of great importance on the evaporation performance of atomized droplet. Spray nozzles with a relatively small flow rate is recommend for the better and complete atomized droplets evaporation.

2) The flue gas temperature, droplet initial diameter and temperature are the dominant impact factors during the evaporation process, while the velocity of droplet, the velocity of flue gas and the nozzle spray full cone angle play minor roles. The spray direction of single nozzle is required to guarantee the dispersion of atomized droplet and heat exchange with flue gas, achieving the maximal evaporation rate.

3) The MISO-LSSVM model can expeditiously and accurately predict the droplet evaporation and be used in the optimization of spray evaporate technology in the practical situation.

Author Contributions: H. Xu: Investigation, Data curation, Writing- Original draft preparation. S. Feng.: Data curation, Investigation. L. Xiao.: Supervision, Reviewing and Editing, Funding acquisition. Y. Hao: Data curation, Funding acquisition X. Du. Conceptualization, Supervision. All authors have read and agreed to the published version of the manuscript.

Funding: This research was funded by National Natural Science Foundation of China (Grant number 52006038) and Science and Technology Project of CHN Energy Cooperation (Grant number GJNY-19-144).

Conflicts of Interest: The authors declare no conflict of interest.

\section{Nomenclature:}

$S_{m} \quad$ source term of mass $\left(\mathrm{kg} \mathrm{m}^{-3} \mathrm{~s}^{-1}\right)$

$S_{m o} \quad$ source term of momentum $\left(\mathrm{kg} \mathrm{m}^{-2} \mathrm{~s}^{-2}\right)$

$S_{e} \quad$ source term of energy $\left(\mathrm{W} \mathrm{m}^{-3}\right)$

$J_{i^{\prime}} \quad$ diffusion flux of species $i^{\prime}\left(\mathrm{kg} \mathrm{m}^{-2} \mathrm{~s}^{-1}\right)$

$h_{i^{\prime}} \quad$ sensible enthalpy of species $i^{\prime}\left(\mathrm{J} \mathrm{kg}^{-1}\right)$

$Y_{i^{\prime}} \quad$ mass fraction of species $i^{\prime}$

$m_{d} \quad$ droplet mass $(\mathrm{kg})$

$c_{d} \quad$ droplet specific heat $\left(\mathrm{J} \mathrm{kg}^{-1} \mathrm{~K}^{-1}\right)$

$d_{d} \quad$ droplet diameter $(\mu \mathrm{m})$

$A_{d} \quad$ droplet surface area $\left(\mathrm{m}^{2}\right)$

$L_{h} \quad$ latent heat of evaporation $\left(\mathrm{J} \mathrm{kg}^{-1}\right)$

$k_{c} \quad$ mass transfer coefficient $\left(\mathrm{m} \mathrm{s}^{-1}\right)$

$k_{f} \quad$ flue gas thermal conductivity $\left(\mathrm{W} \mathrm{m}^{-1} \mathrm{~K}^{-1}\right)$

$h_{c} \quad$ convective heat transfer coefficient $\left(\mathrm{W} \mathrm{m}^{-2} \mathrm{~K}^{-1}\right)$

$N_{u} \quad$ Nusselt number

$P_{r} \quad$ Prandtl number

$R_{e} \quad$ Reynolds number

$S_{c} \quad$ Schmidt number

$S_{h} \quad$ Sherwood number

$B_{m} \quad$ mass Spalding number

$B_{T} \quad$ thermal Spalding number

$C_{D} \quad$ drag force coefficient

$D_{m} \quad$ diffusion coefficient $\left(\mathrm{m}^{2} \mathrm{~s}^{-1}\right)$

$F_{D} \quad$ drag force $(\mathrm{N})$

$T \quad$ temperature $(\mathrm{K})$

u velocity $\mathrm{m} / \mathrm{s}$ 


\section{References}

1. Shi, W.; Lin, C.; Chen, W.; Hong, J.; Chang, J.; Dong, Y.; Zhang, Y. Environmental effect of current desulfurization technology on fly dust emission in China. Renewable and Sustainable Energy Reviews 2017, 72, 1-9, doi:10.1016/j.rser.2017.01.033.

2. Shuangchen, M.; Jin, C.; Gongda, C.; Weijing, Y.; Sijie, Z. Research on desulfurization wastewater evaporation: Present and future perspectives. Renewable and Sustainable Energy Reviews 2016, 58, 11431151, doi:10.1016/j.rser.2015.12.252.

3. Han, X.; Zhang, D.; Yan, J.; Zhao, S.; Liu, J. Process development of flue gas desulphurization wastewater treatment in coal-fired power plants towards zero liquid discharge: Energetic, economic and environmental analyses. Journal of Cleaner Production 2020, 261, doi:10.1016/j.jclepro.2020.121144.

4. Ma, S.; Chai, J.; Chen, G.; Wu, K.; Xiang, Y.; Wan, Z.; Zhang, J.; Zhu, H. Partitioning characteristic of chlorine ion in gas and solid phases in process of desulfurization wastewater evaporation: model development and calculation. Environ Sci Pollut Res Int 2019, 26, 8257-8265, doi:10.1007/s11356-01804070-5.

5. Ma, S.; Chai, J.; Wu, K.; Wan, Z.; Xiang, Y.; Zhang, J.; Fan, Z. Experimental and mechanism research on volatilization characteristics of $\mathrm{HCl}$ in desulfurization wastewater evaporation process using high temperature flue gas. Journal of Industrial and Engineering Chemistry 2018, 66, 311-317, doi:10.1016/j.jiec.2018.05.045.

6. Godin, A. Pretreatment of liquid industrial streams by adsorption: challenges and perspectives. Adsorption-Journal of the International Adsorption Society 2017, 23, 349-353, doi:10.1007/s10450-017-98594.

7. Shuangchen, M.; Jin, C.; Kai, W.; Yajun, X.; Zhongcheng, W.; Jingrui, Z. Experimental and model research on chloride ion gas-solid distribution in the process of desulfurization wastewater evaporation. RSC Advances 2018, 8, 26283-26292, doi:10.1039/c7ra13178j.

8. Córdoba, P. Partitioning and speciation of selenium in wet limestone flue gas desulphurisation systems: A review. Fuel 2017, 202, 184-195, doi:10.1016/j.fuel.2017.04.015.

9. Gingerich, D.B.; Grol, E.; Mauter, M.S. Fundamental challenges and engineering opportunities in flue gas desulfurization wastewater treatment at coal fired power plants. Environ. Sci.-Wat. Res. Technol. 2018, 4, 909-925, doi:10.1039/c8ew00264a.

10. Fu, J.; Hu, N.; Yang, Z.; Wang, L. Experimental study on zero liquid discharge (ZLD) of FGD wastewater from a coal-fired power plant by flue gas exhausted heat. Journal of Water Process Engineering 2018, 26, 100-107, doi:10.1016/j.jwpe.2018.10.005.

11. Koralegedara, N.H.; Pinto, P.X.; Dionysiou, D.D.; Al-Abed, S.R. Recent advances in flue gas desulfurization gypsum processes and applications - A review. J Environ Manage 2019, 251, 109572, doi:10.1016/j.jenvman.2019.109572.

12. Li, C.; Deng, T.; Wen, Z.; Tian, T.; Li, G.; Zhang, Y.; Li, Z. Evaporation experiment and numerical simulation study of desulfurization wastewater in high-temperature raw gas. Chemical Engineering Research and Design 2019, 146, 117-129, doi:10.1016/j.cherd.2019.03.043.

13. Sureshkumar, R.; Kale, S.R.; Dhar, P.L. Heat and mass transfer processes between a water spray and ambient air - I. Experimental data. Applied Thermal Engineering 2008, 28, 349-360, doi:10.1016/j.applthermaleng.2007.09.010. 
14. Tissot, J.; Boulet, P.; Labergue, A.; Castanet, G.; Trinquet, F.; Fournaison, L. Experimental study on air cooling by spray in the upstream flow of a heat exchanger. International Journal of Thermal Sciences 2012, 60, 23-31, doi:10.1016/j.ijthermalsci.2012.06.005.

15. Deng, J.J.; Pan, L.M.; Chen, D.Q.; Dong, Y.Q.; Wang, C.M.; Liu, H.; Kang, M.Q. Numerical simulation and field test study of desulfurization wastewater evaporation treatment through flue gas. Water Sci. Technol. 2014, 70, 1285-1291, doi:10.2166/wst.2014.359.

16. Feng, S.; Xiao, L.; Ge, Z.; Yang, L.; Du, X.; Wu, H. Parameter analysis of atomized droplets sprayed evaporation in flue gas flow. International Journal of Heat and Mass Transfer 2019, 129, 936-952, doi:10.1016/j.ijheatmasstransfer.2018.10.023.

17. Lorenzini, G.; Saro, O. Thermal fluid dynamic modelling of a water droplet evaporating in air. International Journal of Heat and Mass Transfer 2013, 62, 323-335, doi:https://doi.org/10.1016/j.ijheatmasstransfer.2013.02.062.

18. Tissot, J.; Boulet, P.; Trinquet, F.; Fournaison, L.; Macchi-Tejeda, H. Air cooling by evaporating droplets in the upward flow of a condenser. International Journal of Thermal Sciences 2011, 50, 2122-2131, doi:https://doi.org/10.1016/j.ijthermalsci.2011.06.004.

19. Montazeri, H.; Blocken, B.; Hensen, J.L.M. CFD analysis of the impact of physical parameters on evaporative cooling by a mist spray system. Applied Thermal Engineering 2015, 75, 608-622, doi:https://doi.org/10.1016/j.applthermaleng.2014.09.078.

20. Collin, A.; Boulet, P.; Parent, G.; Lacroix, D. Numerical simulation of a water spray-Radiation attenuation related to spray dynamics. International Journal of Thermal Sciences 2007, 46, 856-868, doi:https://doi.org/10.1016/j.ijthermalsci.2006.11.005.

21. Kim, H.; Sung, N. The effect of ambient pressure on the evaporation of a single droplet and a spray. Combustion and Flame 2003, 135, 261-270, doi:10.1016/s0010-2180(03)00165-2.

22. Alkhedhair, A.; Gurgenci, H.; Jahn, I.; Guan, Z.; He, S. Numerical simulation of water spray for precooling of inlet air in natural draft dry cooling towers. Applied Thermal Engineering 2013, 61, 416-424, doi:10.1016/j.applthermaleng.2013.08.012.

23. Alkhedhair, A.; Jahn, I.; Gurgenci, H.; Guan, Z.; He, S.; Lu, Y. Numerical simulation of water spray in natural draft dry cooling towers with a new nozzle representation approach. Applied Thermal Engineering 2016, 98, 924-935, doi:10.1016/j.applthermaleng.2015.10.118.

24. Alkhedhair, A.; Jahn, I.; Gurgenci, H.; Guan, Z.; He, S. Parametric study on spray cooling system for optimising nozzle design with pre-cooling application in natural draft dry cooling towers. International Journal of Thermal Sciences 2016, 104, 448-460, doi:10.1016/j.ijthermalsci.2016.02.004.

25. Zhang, Y.X.; Wang, X.; Zhang, H.D.; Liu, J.Y.; Luan, T. Numerical simulation of WFGD wastewater with atomizing and crystallization treatment. Energy Sources Part A-Recovery Util. Environ. Eff. 2020, 42, 1268-1285, doi:10.1080/15567036.2019.1604852.

26. Hou, Y.; Tao, Y.; Huai, X.; Guo, Z. Numerical characterization of multi-nozzle spray cooling. Applied Thermal Engineering 2012, 39, 163-170, doi:10.1016/j.applthermaleng.2012.01.030.

27. Suykens, J.A.K.; Vandewalle, J. Least squares support vector machine classifiers. Neural Processing Letters 1999, 9, 293-300, doi:10.1023/A:1018628609742.

28. Wu, Q.; Liu, W.Y.; Yang, Y.H. Time series online prediction algorithm based on least squares support vector machine. Journal of Central South University of Technology (English Edition) 2007, 14, 442-446, doi:10.1007/s11771-007-0086-0. 
29. Liu, H.; Wang, S.; Liu, J. LS-SVM prediction model based on phase space reconstruction for dam deformation. In Advanced Materials Research, 2013; Vol. 663, pp 55-59.

30. Asfaram, A.; Ghaedi, M.; Azqhandi, M.H.A.; Goudarzi, A.; Dastkhoon, M. Statistical experimental design, least squares-support vector machine (LS-SVM) and artificial neural network (ANN) methods for modeling the facilitated adsorption of methylene blue dye. RSC Advances 2016, 6, 40502-40516, doi:10.1039/C6RA01874B.

31. Li, X.; Zbiciński, I. A sensitivity study on CFD modeling of cocurrent spray-drying process. Drying Technology 2005, 23, 1681-1691, doi:10.1081/DRT-200065093.

32. Montazeri, H.; Blocken, B.; Hensen, J.L.M. Evaporative cooling by water spray systems: CFD simulation, experimental validation and sensitivity analysis. Building and Environment 2015, 83, 129-141, doi:https://doi.org/10.1016/j.buildenv.2014.03.022.

33. Sazhin, S.S. Advanced models of fuel droplet heating and evaporation. Prog. Energy Combust. Sci. 2006, 32, 162-214, doi:10.1016/j.pecs.2005.11.001.

34. Ranz, W.E.; Marshall, W.R. Evaporation from drops: I. Chemical Engineering Progress 1952, 48, 141-146.

35. Ranz, W.E.; Marshall, W.R. Evaporation from drops: II. Chemical Engineering Progress 1952, 48, 173-180.

36. Jen, T.C.; Li, L.; Cui, W.; Chen, Q.; Zhang, X. Numerical investigations on cold gas dynamic spray process with nano- and microsize particles. International Journal of Heat and Mass Transfer 2005, 48, 43844396, doi:10.1016/j.ijheatmasstransfer.2005.05.008.

37. Chu, F.; Xiao, G.; Yang, G. Mass transfer characteristics and energy penalty analysis of MEA regeneration process in packed column. Sustainable Energy and Fuels 2021, 5, 438-448, doi:10.1039/d0se01251c.

38. Chen, W.X.; Chong, D.T.; Yan, J.J.; Dong, S.C.; Liu, J.P. Numerical Investigation of Two-Phase Flow in Natural Gas Ejector. Heat Transf. Eng. 2014, 35, 738-745, doi:10.1080/01457632.2013.838069.

39. Liu, A.B.; Mather, D.; Reitz, R.D. Modeling the effects of drop drag and breakup on fuel sprays. $S A E$ Technical Papers 1993, 10.4271/930072, doi:10.4271/930072. 